\title{
Novel Attribute of Organic-Inorganic Hybrid Coatings for Protection and Preservation of Materials (Stone and Wood) Belonging to Cultural Heritage
}

\author{
Mariaenrica Frigione ${ }^{1, *(D)}$ and Mariateresa Lettieri ${ }^{2}$ (D) \\ 1 Department of Engineering for Innovation, University of Salento, 73100 Lecce, Italy \\ 2 Institute of Archaeological Heritage-Monuments and Sites, CNR-IBAM, Prov.le Lecce-Monteroni, \\ 73100 Lecce, Italy; mariateresa.lettieri@cnr.it \\ * Correspondence: mariaenrica.frigione@unisalento.it; Tel.: +39-0832-297-215
}

Received: 4 July 2018; Accepted: 6 September 2018; Published: 10 September 2018

\begin{abstract}
In order to protect a material belonging to Cultural Heritage (i.e., stone, wood) from weathering, and in turn to preserve its beauty and historical value for the future generations, the contact with external harmful agents, particularly water, must be avoided, or at least limited. This task can be successfully obtained with the use of a protective organic coating. The use of nano-metric reinforcing agents in conventional polymeric coatings demonstrated to be a successful route in achieving better protective performance of the films and improved physical properties, even in extreme environments. The present paper would, therefore, review the more recent findings in this field. Generally speaking, when a hydrophobic product is applied on its surface, the stone material will absorb less water and consequently, less substances which may be harmful to it. An efficient organic coating should also supply wear and abrasion resistance, resistance to aggressive chemicals, excellent bond to the substrate; finally, it should be also able to guarantee vapor exchange between the environment and the material interior, i.e., the material should keep the same water vapor permeability as if it was un-protected. To regard to the conservation of wood artifacts, protective treatments for wood will preserve the material from environmental agents and biological attack. Hence, potential advantages of hybrid (organic-inorganic) nano-composite coatings for stone/wood have been found to be: Enhanced mechanical properties in comparison to the pure polymeric matrix, due to the reinforcing effect of the nano-filler; superior barrier properties (the presence of the nano-filler hinders the ingress of water and/or potentially harmful chemicals); optical clarity and transparency. It has been found that the efficacy of a nano-filled coating strongly depends on the effectiveness of the method used to uniformly disperse the nano-filler in the polymeric matrix. Furthermore, the presence of nano-particles should not impair the viscosity of the organic matrix, in order to employ the conventional techniques of application for coatings.
\end{abstract}

Keywords: coatings; nanosilica; nano- $\mathrm{TiO}_{2}$; nano-clay; stone conservation; wood protection

\section{Introduction}

As recommended by conservation professionals of historic monuments and building, a protective product for stone surfaces must be able to: protect the stone from external agents and guarantee a high level of hydrophobicity, avoiding in particular the ingress of water, considering that water and water-soluble salts represent the main causes of degradation mechanisms; allow the transpiration of the stone, in order to avoid that the water already present in the substrate can cause further degradation; not alter the color and other optical characteristics—like gloss—of the substrate; be reversible, to permit an easy removing of the coating when it will result no more effective with no damage of the substrate. In addition, an ideal coating should be also stable, durable, easy to apply and non-toxic. 
The protection of ancient stone monuments and buildings from the attack of environmental agents and atmospheric pollution is frequently carried out employing polymer-based surface treatments. Polymeric coatings, produced starting mainly from acrylic/methacrylic monomers, unsaturated polyesters, fluorinated polymers, epoxy resins, silanes and siloxanes, are able to form hydrophobic and completely transparent films, capable to limit the ingress of fluids into the stone. Among other advantages, their possibility to develop high mechanical resistance upon curing and hardening under a wide range of environmental conditions, low weight, also due to the small thicknesses required for an efficient protection, wear and abrasion resistance, good bond exerted to stone [1,2]. In some cases, they demonstrated also capacity of acting as consolidants. The limited durability, especially for acrylic-based coatings showing poor photo-oxidative stability when outdoor exposed, on the other hand, poses heavy concerns on their wider use when a long-term protection of archaeological and historical items and structures is of fundamental importance. The treatment efficacy (hydrophobic properties) of fluorinated polymers decreases dramatically with time [3].

Polymeric nano-composites based on nano-sized inorganic (aluminum oxide, clay, calcium carbonate, silica, and titanium dioxide) particles dispersed in the polymeric matrix are increasingly becoming a viable alternative to commercial polymeric coatings for stone due to their superior properties compared either to the pure polymer and to conventional micro-composites, especially in terms of barrier effect, higher resistance to temperatures, hash environments, fire and flame, and durability performance [4].

Durability of wood artifacts and structures, due to the timber microstructure and porosity, is strongly affected by exposure to environmental agents, mainly water/moisture presence, and microbial attacks [5]. Superficial protection and wood impregnation with chemical treatments are well known effective methods to limit the water absorption, improve the biological resistance and enhance the durability of wood. Among the most effective products for the protection of wood: aldehydes, ethyleneurea formulations, polyurethane, unsaturated polyesters, phenolic or melamine resins, acrylic and metacrylic monomers [6]. As already mentioned, acrylic based coatings display poor durability when the wood items/structures to protect are outdoor exposed. Furthermore, the most of protective coatings for wood are applied in solvent, thus during their application VOC (volatile organic compounds) can be released, representing a severe hazard for human beings and the environment.

Nano-filled coatings have been proposed for the protection of wood from biological and environmental attacks, being able to overcome some of the mentioned drawbacks. In addition, enhanced mechanical superficial characteristics (resistance against abrasion and wear), impact strength and fracture toughness, improved resistance to flame, fire and moisture can be achieved with the introduction of an inorganic nano-filler in a protective organic coating [6].

\section{Nano-Clay}

The more attractive properties of clay nano-particles as additive for coatings can be summarized in their: availability, low costs if compared to those displayed by other nano-particles, low toxicity and concerns for environment, good reactivity and catalytic properties [7]. Furthermore, the addition of nano-clay in polymeric coatings confer them remarkably improved mechanical properties (i.e., stiffness and strength) and hydrophobicity characteristics, as well as thermal and flame resistance [8], as a consequence of unique interfacial properties generated at nano-metric level. Due to the great specific surface area of nano-clay, furthermore, high barrier characteristics can be also achieved, important features for protective coatings for stone surfaces. The incorporation of nano-clay at low loadings, i.e., not greater than $10 \%$, in organic (especially acrylic-based) coatings has been found to appreciably enhance the properties and the durability also of wood. Due to their small size, in fact, the nano-particles are able to easily penetrate into the wood cells.

Referring to the transparency and optical properties, the size of nano-particles, smaller than the wavelength of visible light, reduces the chance of light interacting with the nano-clays, especially if they are well dispersed in the organic matrix. This allows nano-filler to be introduced into a coating 
without impairing its transparency. Several studies have demonstrated, in fact, that, if limited amounts of nano-clay particles are appropriately dispersed in a polymeric matrix, good optical clarity can be achieved. However, the introduction of nano-clay at high loading (i.e., $10 \mathrm{wt} \%$ ) in a polymeric matrix leads to a reduction of the degree of transmitted visible light through the coating with respect to the purely polymeric film, due to the light scattering by clay nano-particles, possibly aggregated $[9,10]$.

In relation to the glass transition temperature $\left(T_{\mathrm{g}}\right)$, an increase of this property has been registered in clay nano-composites, attributed to a restriction in macromolecular mobility due to the presence of silicate nano-particles [11].

\subsection{Methods of Preparation and Dispersion}

The effectiveness of a protective coating depends on its chemical nature, its composition, comprising the presence of suitable additives, and on the production and application methods.

The traditional techniques employed to obtain micro-composites (i.e., blending/extrusion in melt state or in solution, in situ polymerization) can be extended also to clay nano-composites provided that an adequate dispersion of the nano-filler is achieved. In the case of in situ polymerization, the intercalation of polymer macromolecules into the clay galleries is followed by a thermo/UV-activated processes, i.e., a free radical or a ring-opening polymerizations. Photo-polymerization is defined as the cure process of a thermosetting resin induced by UV/solar light. This fairly new technology is economical and environmentally-friendly, since solvent-free mixtures can be fast hardened after their deposition as low-thickness coatings on a substrate.

Generally speaking, the production and application of a nano-filled coating presents some difficulties and requires the identification of proper procedures, with possibly greater processing temperatures and times. In the case on montmorillonite (abbreviation: MMT), the preparation method must guarantee the nano-filler exfoliation inside the matrix resin.

As an example, the most used procedure in the preparation of the nano-filled coatings is the dispersion method, where both, the nano-filler and the polymeric matrix, are solubilized in a solvent; the solvent is, eventually, removed through evaporation. In order to promote the dispersion of the nano-filler, this procedure can be enhanced through magnetic/mechanical stirring or sonication in an ultrasonic bath at appropriate temperatures. It has been demonstrated that dispersed nano-clays introduced in a mix of acrylate resins using ultrasonication techniques supply to the un-filled coatings enhanced mechanical properties [12]. Nevertheless, the production method was quite long and difficult to extend to industrial scale.

In the case of coatings based on un-saturated polyester resin and functionalized MMT powder, it was found that the performance of the MMT nano-filled coating were appreciably affected by the mixing time, being the influence of this parameter of processing comparable with the effect of the MMT content [13].

Since a good dispersion of the nano-particles in the polymeric matrix is one of the key factor for a true enhancement of final properties and performance of the matrix [14], a proper modification of the hydrophilic surface nano-particles could be necessary. In such way it is possible to increase the compatibility between a nano-sized clay and the polymeric matrix and to obtain an homogeneous and more stable dispersed nano-filled suspension in liquid state. The superficial modification of the nano-clay, as well as its loading into the polymeric matrix, can also have a remarkable effect on the extent of cure of the polymeric coating.

In some case, water-based dispersions of nano-particles are preferred in order to avoid the aggregation of nano-particles both in the wet state of the coating and in the hardened state of the protective film.

\subsection{Relevance of Viscosity for the Application}

The assessment of the viscosity of the un-cured coating is essential to identify the proper procedure (for instance, using a brush, by spray or capillary rising) to apply the liquid product on the substrate 
to protect. In addition, the viscosity can also be affected by the preparation procedure employed to produce the nano-filled coating [13]. On the other hand, by increasing the resin viscosity, it becomes more difficult to produce thin coatings. Therefore, rheological studies must be performed in order to quantify the effect of the presence of the nano-filler on the viscosity of the liquid coating and to optimize the parameters for the production technique.

\subsection{Montmorillonite}

Among smectite class of aluminum silicate clays (i.e., those possessing layered silicate particles), montomorillonite (MMT), whose structure is shown in Figure 1, has gained the major attention both within the academia and industrial research for the production of polymer-based nano-composites, giving rise to well-developed intercalated nano-sized structures $[15,16]$.

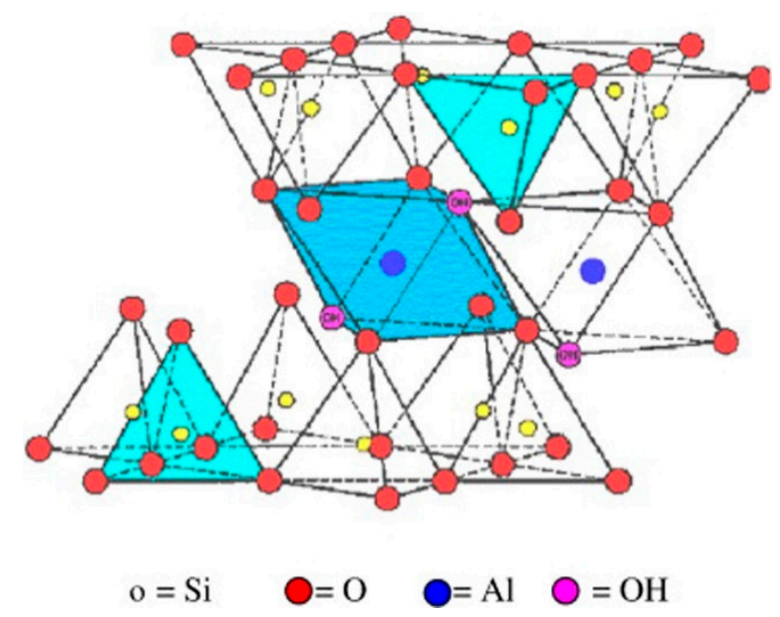

Figure 1. Molecular structure of montmorillonite. Reprinted with permission from [16]. Copyright 2008 Elsevier.

A hybrid composite, composed by an organic matrix and MMT nano-filler, can display the three different following morphologies [17]: (i) incompatible one, when clay tactoids are not dispersed in the organic matrix; (ii) intercalated morphology, in this case the layered silicates are expanded in such a way that the polymer macromolecules can enter them, still surviving an ordered structure; and (iii) exfoliated morphology, when the single layered silicates are completely separated and uniformly distributed in the organic matrix, depending their average distances on the clay loading (see schemes in Figure 2). This latter morphology has been found to supply better final properties to the polymer/nano-clay systems [18].

Layered silicate nano-particles display intrinsically improved properties, such as: (i) a high aspect ratio, responsible for their platelet aspect; (ii) a large specific surface area $\left(750-800 \mathrm{~m}^{2} / \mathrm{g}\right.$ ); and (iii) greater Young modulus with respect to nano-sized silica particles [19]. The structure of layered silicate nano-particles when exfoliated into the polymer, i.e., high aspect ratio and high surface area, are responsible for the enhanced properties of their nano-composites, in particular barrier capability. The silicate type (structural features) and its loading in polymeric matrix will affect the final properties and performance of the resulting nano-composite. A small quantity (typically not greater than $5 \mathrm{wt} \%$ ) of layered nano-clays can guarantee a large interfacial area with the polymeric matrix, provided that the nano-filler is properly dispersed into the matrix [15]. An appropriate chemical modification of the hydrophilic surface of MMT nano-clays is frequently carried out with the aims to favor their compatibility with different polymers with the additional advantage to increase the interlayer distance, thus facilitating the ingress of the macromolecules during the dispersion process [15]. 


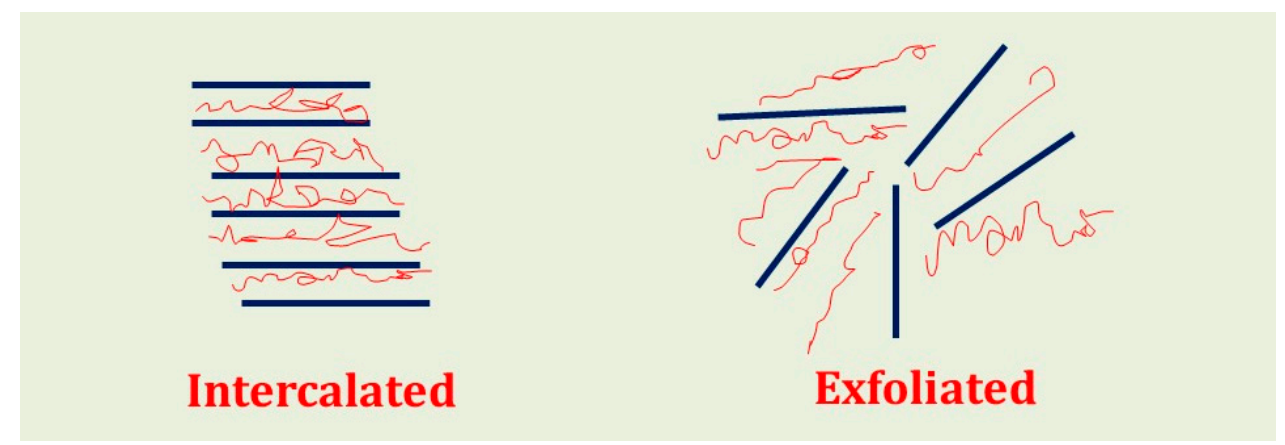

Figure 2. Schematically illustration of intercalated and exfoliated morphologies displayed by polymer/layered silicate nano-composite.

\subsubsection{Montmorillonite/Stone}

Only few examples on the use of polymeric coatings based on montmorillonite for the protection of stone surfaces are reported in literature.

Experimental coatings produced starting from a commercial formulation, based on a blend of acrylic and vinylidenfluoride-based polymers, and different amounts (not greater than $4 \mathrm{wt} \%$ ) of an organically modified MMT (i.e., Cloisite 30B) were tested as protective/consolidating agents for a porous stone typical of the Campania region in Italy, i.e., the Neapolitan yellow tuff [20]. It was found that the addition of low amounts of the organoclay nano-filler into the commercial polymeric formulation allows to achieve reductions in both water absorption and water vapor permeability. Enhanced mechanical properties and abrasion resistance were also observed, suggesting that the nano-composites display also consolidating capability. In addition, the chromatic appearance of the stone was not altered by the MMT-based coating.

Water-based nano-composite, obtained by dispersing low amounts (up to $5 \mathrm{wt} \%$ ) of MMT (neat or organically modified) nano-particles into a cross-linked fluorinated polyurethane based on perfluoropolyethers, were analyzed as possible anti-graffiti coating for Leccese stone, a very porous stone characteristic of Apulian region [21]. It was found that organically modified MMT when introduced (in particular at $3 \mathrm{wt} \%$ ) in the polymeric matrix is able to supply a high hydrophobicity to the stone and a stable anti-graffiti effect for black acrylic spray paint; this latter, in fact, can be easily removed from the stone using MEK (methyl ethyl ketone) solvent, leaving the stone surface substantially unaffected from an aesthetical and morphological point of view, even after repeated staining/cleaning cycles (as shown in Figure 3). Unsatisfactory results were found when the leccese stone surface was staining by a black ink permanent marker. Irrespective to the MMT nano-filler employed, in fact, the coatings were able to protect the stone only for the first staining/cleaning cycle. After repeated cycles, on the other hand, the marker is able to penetrate the nano-filled coatings and the solvent employed to clean the surface, i.e., IPA (Isopropyl alcohol), is no more able to remove the black ink. Furthermore, a noteworthy drawback observed for the nano-composite coatings was a significant reduction in water vapor permeability brought about by their application on Leccese stone. However, this inconvenience was mainly attributed to the cross-linked nature of the fluorinated polyurethane able to hinder to a certain extent the transport of water vapor exiting from the stone.

In a different study, montmorillonite clay (up to $7 \mathrm{wt} \%$ ) was added to a biodegradable polymer (poly-L-lactide, PLA), obtaining bio-nano composite coatings proposed for the protection of marble against pollution [22]. With the application of the protective coating, significant improvements in hydrophobicity were registered on the marble, both capillary water absorption and transport of water vapor were reduced, both attributed to the presence of exfoliated MMT nano-clays hindering the water movements inside the polymeric coating. The chromatic appearance of the surface remaining unchanged with the application of the bio-nano composite coating. In addition, a greater resistance of the marble to acidic atmosphere was registered. Finally, due to the nature of PLA matrix, it is expected a limited biodegradability of the MMT coating, that will suggest a reversibility of the treatment. 

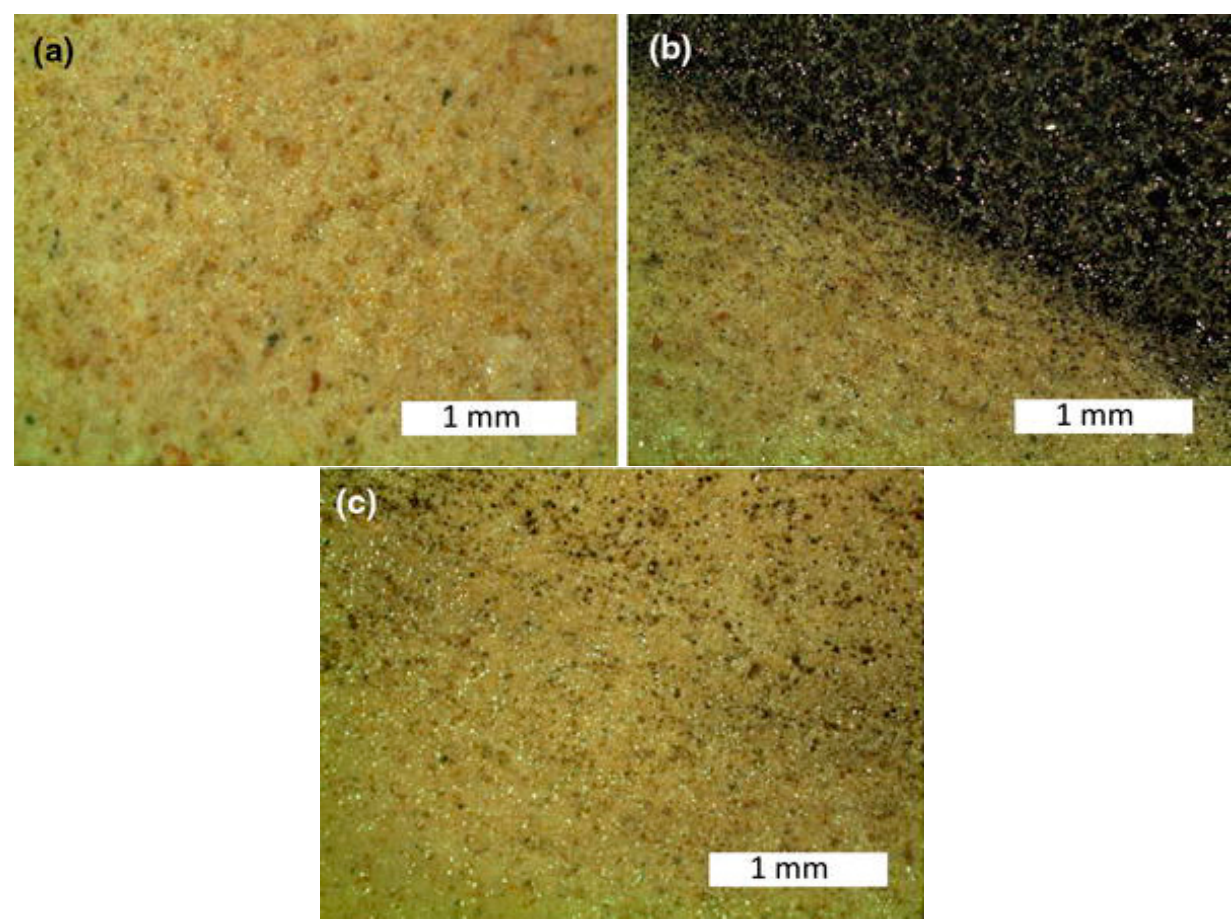

Figure 3. Micro-graphs at reflected light showing Lecce Stone surface: (a) after treatment with nano-composite containing 3 wt \% of organically modified montmorillonite; (b) after staining by spray paint (upper right area in the picture); and (c) after 8 consecutive staining/cleaning cycles. Reprinted with permission from [21]. Copyright 2014 Springer.

\subsubsection{Montmorillonite/Wood}

Several are the recent examples of MMT-based nano-composite coatings for the protection of wood surface reported in literature. Even though most of the experimented hybrid systems are proposed for wood employed in modern floor, furniture or topping, such products could be extended also for the protection of wood artifacts and timber of valuable ancient structures.

The effect of dispersion method employed to introduce modified nano-composites based on MMT (i.e., Cloisite modified with a quaternary ammonium salt) in acrylate oligomers to produce UV-cured coatings for sugar maple wood [9]. The effect of process type, in particular of the quality of the clay dispersion, and of clay loading (1-10 wt \% of modified Cloisite) on surface-mechanical properties and optical characteristics of the coatings was assessed. Both these parameters were found to appreciably affect the mechanical and optical properties of the nano-coatings. It was found that at small clay loadings (not greater than $3 \mathrm{wt} \%$ ), with a suitable dispersion technique, nano-composite UV-cured acrylic coatings with significant mechanical and optical properties can be produced for the protection of wood, mainly for flooring applications.

In other studies, three different commercial organically modified Montmorillonite (i.e., Cloisite 10A, Cloisite 15A and Cloisite 30B) were added (1 and $3 \mathrm{wt} \%$ ) to an UV-cured epoxy-acrylate oligomer intended as protective coatings for wood furniture $[19,23]$. The Authors assessed that not all the clay nano-fillers were well dispersed in the acrylic matrix, and only $\mathrm{C} 10 \mathrm{~A}$ and $\mathrm{C} 15 \mathrm{~A}$ give rise to an intercalated morphology in the UV-cured nano-composites, irrespective to the nano-filler content. The kind and amount of added organo-clays affected both the water vapor transmission rate and the optical transparency, both generally decreased upon addition of MMT nano-particles. C10A seemed to supply the best performance to the organic coating. The presence of low amounts of organo-clays is also able to enhance the mechanical properties and glass transition temperature of the pure resin, particularly for nano-composites based on C10A. It can be concluded that the presence of low amounts of a suitable organo-clay in an acrylic matrix can confer better mechanical properties and an increase of 
$T_{\mathrm{g}}$ to the UV-cured film. The resulting organic nano-filled coating also displays a limited deformability, which represents an advantage in comparison to the inorganic protective products.

The effect of nano-clays addition to nano-composites based on $\mathrm{TiO}_{2} /$ acrylic transparent coatings applied on Norway spruce was assessed in several studies $[7,24,25]$. Accelerated weathering tests assessed that the presence of low amount $(1 \mathrm{wt} \%)$ un-modified nano-clay (bentonite, i.e., colloidal clay consisting primarily of MMT) in combination with $\mathrm{TiO}_{2}$ nano-particles is able to supply enhanced resistance towards UV radiation to the acrylic coatings, delaying the photo-degradation process of protective coatings, the latter keeping transparency upon outdoor exposure. At slightly greater amounts (i.e., $3 \mathrm{wt} \%$ ), the sole presence of nano-clay in the water based acrylic coating is still able to retard to a limited extent the degradation of wood surface.

\section{Boehmite}

Boehmite $\left(\mathrm{c}-\mathrm{Al}_{2} \mathrm{O}_{3}\right)$ nano-particles are colloidal plate-like crystals. As shown in Figure 4, Boehmite crystals, characterized by a high anisotropy, consist of double layers of oxygen octahedrons with a central $\mathrm{Al}$ atom [26]. An important feature of Boehmite is that it may have a very high specific surface area $\left(>300 \mathrm{~m}^{2} / \mathrm{g}\right)$, suggesting its use as nano-filler in polymeric materials. Furthermore, Boehmite nano-particles are largely available on market at reasonable costs; their surface can be easily treated (with proper coupling agents) to assume hydrophobic/hydrophilic character, enhancing their dispersion in various polymeric matrices.

Upon their addition to a polymeric resin, organically modified Boehmite nano-particles were found to increase the $T_{\mathrm{g}}$, the hardness and mechanical strength of a cured epoxy resin [27], being the latter all attractive characteristics for a protective coating for stone or wood.

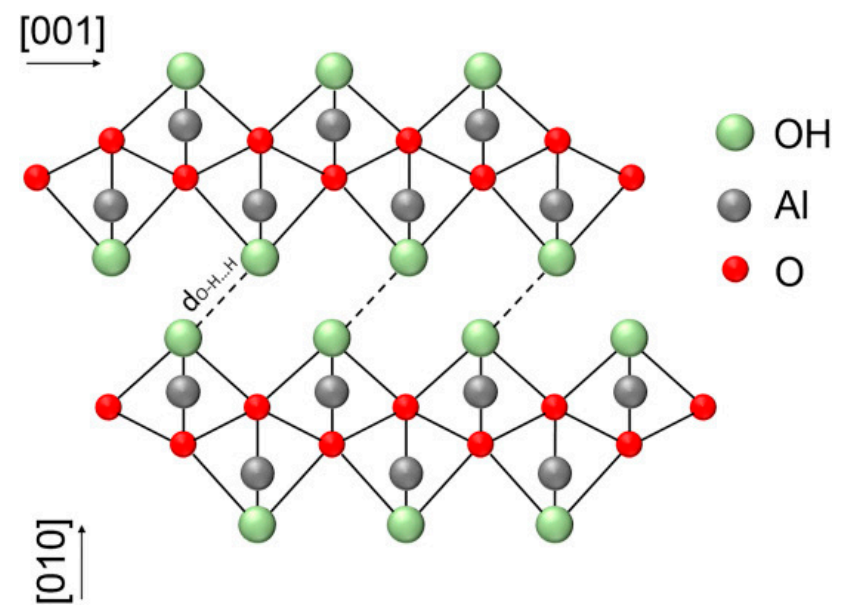

Figure 4. Molecular structure of Boehmite. Reprinted with permission from [26]. Copyright 2017 John Wiley \& Sons.

Referring to the production techniques, the addition of organo-modified Boehmite (amounts in the range $5-10 \mathrm{wt} \%$ ) to a UV-cured cycloaliphatic epoxy resins, to obtain in situ photo-polymerized nano-composite coatings, resulted in a reduction of the epoxy resin reactivity. This un-desirable effect was attributed to the light absorbance of the nano-particles due to scattering [28]. However, the final properties of the coating, i.e., high transparency and glass transition temperature, were suitable for protection applications in Cultural Heritage field, especially when modified Boehmite was added to the epoxy matrix at low loadings. On the other hand, when organically modified Boehmite (up to $5 \mathrm{wt} \%$ ) was added to a DGEBA (diglycidyl ether of bisphenol A) epoxy, both the cure kinetic of the resin and its degree of cross-linking were increased [27]. Similar results were found for the same nano-filler, which was added to a siloxane-modified methacrylic resin: the conversion of reactive species in the organic matrix was found, in fact, to be increased by the presence of Boehmite nano-particles, remaining fairly unaffected the kinetics of cross-linking [14]. 
Referring to processability characteristics, a general increase in the viscosity of the polymeric resin was observed with increasing the amount of organically modified Boehmite nano-particles, especially at very high loading amounts (up to $20 \mathrm{wt} \%$ ), irrespective to the chemical nature of the epoxy matrix $[14,27,29]$.

\subsection{Boehmite/Stone}

$\mathrm{UV} /$ sunlight curable nano-composites suitable for stone protection were produced starting from an experimental siloxane-modified methacrylic formulations with the addition of organo-modified boehmite (OMB) [30]. The presence of nano-particles uniformly dispersed in the thermosetting polymer allows to increase its hydrophobicity, hardness and superficial resistance to scratch. The nano-composite coating displays complete transparency and slightly greater $T_{\mathrm{g}}$ as compared with the unfilled UV-cured modified methacrylic resin. An increase in thermal conductivity was also registered upon addition of OMB nano-particles into the polymeric resin [31].

Referring to durability characteristics, after two subsequent cycles of accelerated aging (duration $100 \mathrm{~h}$ each), the surface functional properties of the protective coatings ( $T_{\mathrm{g}}$, contact angle, hardness) slightly increased and, then, remained unaffected. The presence of nano-particles was able to reduce, but not to completely avoid, the yellowing effect due to prolonged exposure (four cycles) to the UV-lamp in the accelerated weathering machine.

The experimental sunlight-cured nano-composite was, then, applied to two different calcareous stones (i.e., Leccese and Gentile stones, typical of Apulia region) in order to assess its performance as protective coating for stone substrates [4,31]. The organo-modified Boehmite-based nano-composite coating showed a noticeable hydrophobic character (as shown in Figure 5), demonstrated to be able to reduce appreciably the ingress of liquid water in both experimented stones. It was completely transparent and no chromatic variation was registered on both stones upon its application. The good breathability assessed for the experimental coating applied on both stones is maintained even after prolonged outdoor exposure or an accelerated aging procedure [32]. The good protective properties and durability performance assessed for the nano-composite coating were found even greater than those measured on two commercial organic water-borne hydrophobic products. A further advantage of the OMB-based coating over commercial products is the complete absence of any solvent in the liquid uncured formulation, so it can be truly considered as a "green" product.

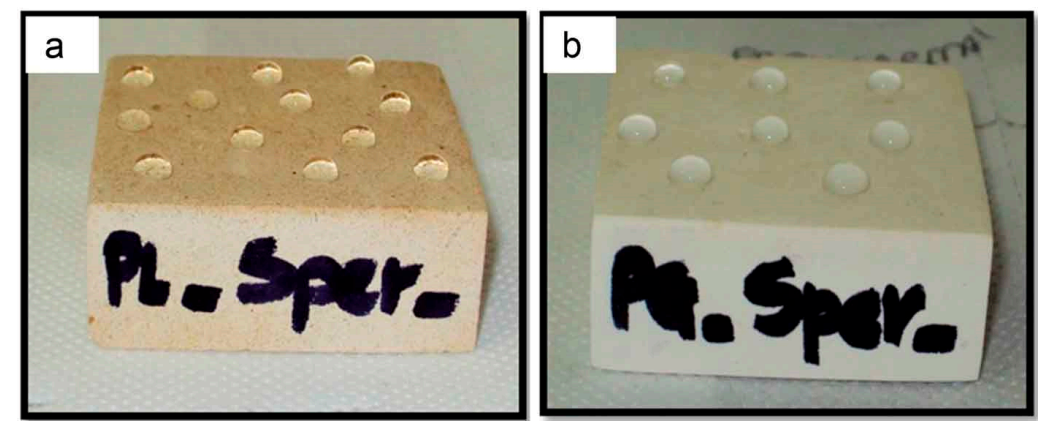

Figure 5. Measurements of contact angle performed on (a) Leccese stone and (b) Gentile stone specimens, both treated with Boehmite-based nano-composite coating. Reprinted with permission from [32]. Copyright 2017 Elsevier.

\subsection{Boehmite/Wood}

The nano-composite UV-cured coating, produced starting from a siloxane-modified acrylic formulation with the addition of an organo-modified Boehmite, successfully experimented on stone was, then, proposed for the protection of walnut wood [14,33]. A high penetration depth, comparable to that measured on commercial products (based on linseed oil) was assessed for the nano-filled modified-acrylic liquid formulation. The wood surfaces treated with the nano-composite resulted 
highly hydrophobic and absorbed smaller amount of water with respect to commercial coating. The transparency of the coating film remained unaffected by the presence of OMB, with a small chromatic alteration of the wood substrate, even lower than that measured for the commercial product. Along with an enhancement in surface hardness, the presence of a low amount (at $3 \mathrm{wt} \%$ ) of organically-modified nano-particles produced an increase in $T_{\mathrm{g}}$ in comparison to the unfilled acrylic mixture. As previously underlined, the liquid formulation is completely solvent-free, this latter representing a double advantage: the absence of any toxic-hazardous solvent and the drastic reduction of the hardening time of the coating, passing from 1 week, required to achieve the complete evaporation of solvents in the commercial product, to few (six) hours, necessary to complete the photo-polymerization process in the nano-composite coating.

\section{Nanosilica}

Several methods have been used to design and produce superhydrophobic/oleophobic stone surfaces, hierarchically structured (Figure 6) [2] and often bioinspired. The most common procedures include sol-gel processes and controlled nano-particle embedding into polymer matrices. This latter is usually a simple method, having low costs, because common polymers, nano-particles and solvents need to be used. The obtained hybrid polymer films, applied on the stone surface, are able to reduce the surface tension of the substrate, thus increasing the surface hydrophobic properties. Hydrophobicity can be further enhanced by increasing the surface roughness. To this aim, the addition of nano-particles has been found very useful and effective. Among them, nano-scale $\mathrm{SiO}_{2}$ particles have been widely applied.

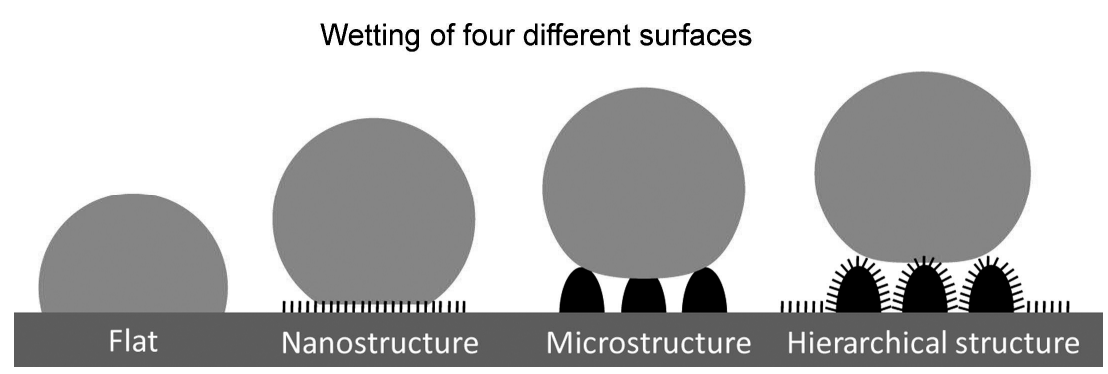

Figure 6. Schematic of four different surface structure types and their wetting behaviors. Reprinted with permission from [34]. Copyright 2016 Elsevier.

\subsection{Preparation and Properties of Nanosilica Hybrids}

Nano-scale silica $\left(\mathrm{SiO}_{2}\right)$ particles do not have the narrow gallery structure of layered clay, but possess a large interfacial area as long as the diameter of the particles is in the range of nano-meters, and they can be well dispersed in polymers [35]. On the other hand, nanosilica alone works quite well only as a consolidant, but exhibits poor results on carbonate substrates, probably due to the incompatibility of such product with the stone [36].

Silicon dioxide nano-particles (from $0.1 \%$ to $8 \%$ ) have been added to polymer based on silanes/siloxanes [37-39], fluoropolymers [40,41], polyurethanes [42,43], polyurethane-acrylate [44], methacrylic resins [45,46], unsaturated polyester resin [47], DGEBA-amine epoxy resins [48,49]. In these hybrids, silica nano-particles usually have dimensions around 7-14 $\mathrm{nm}$ in mean diameter [37,38].

After the nano-particles' addition, the mixture with polymer(s) can be subjected to sonication $[42,48,50,51]$ or vigorous stirring in order to prepare an optimal and homogeneous dispersion $[37,47,52]$. However, sometime the stirring procedure did not ensure nano-particles homogeneously dispersed in the polymer film; SEM (scanning electron microscopy) observations highlighted aggregates with average diameters dependent on the nano-particles concentration [38,52]. Sonication has been found useful to change the basic rheological properties of polymers by partial 
disintegration of the primary polymer chain structure and cavitation exerts, thus impacting on the ability of polymers to well penetrate and fill the pores of the stone substrate [51].

The preparation through a sol-gel process is usually carried out via co-condensation of compounds containing $-\mathrm{Si}(\mathrm{OR})_{3}$ moieties (such as tetra-ethyl-orthosilicate (TEOS) $[43,45]$ ) and a polymer (polydimethylsiloxane (PDMS) [53-55], trimethoxysilyl-propyl methacrylate (TMSPMA) [56]), in the presence of a surfactant (n-octylamine [53,54,57], dodecylamine [56]). In the processes where techniques based on two-stages [56], that is sol-gel and free-radical polymerization, have been applied to obtain hybrid nano-composites, the 2,2-azobis(2-methylpropionitrile) (AIBN) and / or acids can be used as additional reagents. A preliminary functionalization of the silica nano-particles (for example with 1,1,1-Trimethyl- $N$-trimethylsilyl-silanamine) is sometime performed [38].

In the sol-gel process, hydrolysis reaction rate plays a critical role: when hydrolysis is sufficiently rapid to provide hydrolyzed products that can condense with the polymer component (e.g., silanol-terminated PDMS), a homogeneous organic-inorganic hybrid gel is obtained. The surfactant is able to modify the hydrolysis/condensation process, because of a change in $\mathrm{pH}$ of the solution which modify the rate of hydrolysis; an increased $\mathrm{pH}$ of the solution increases the level of hydrolysis [54].

The physical properties of nanosilica-based hybrids mainly depend on the synthesis procedure, which affects the specific surface, the dimensions of the primary particles and aggregates, and the coating' porosity. The differences between these physical characteristics are strictly correlated to the organization of the silica particles (as aggregates or agglomerates) [56].

Nanosilica can be observed in aggregated state with the different size and shape, depending on the type of matrix. In fact, the dispersion of the nano-particles depends on the extent of interactions between them as well as on the polymer/nanoparticles interactions [58]. Increasing the nanoparticles' loading results in an increase in both the size and number of the nanosilica aggregates [59] and a decrease in the inter-aggregate distance, up to obtain a fractal structure $[58,60]$. In these cases, nanoparticles in agglomerates interact directly with each other with this attraction prevailing over all the interfacial interactions in the system [60].

The materials synthesized using a surfactant exhibit high surface area, high pore volume, and a structure having uniform mesopores [53,54]. Since the capillary pressure in the gel network during drying is inversely proportional to the gel pore size, the coarsening of the gel pores promotes a lower capillary pressure, thus, preventing cracking. The polymer itself can prevents cracking, by increasing the flexibility of the silica skeleton and the shrinkage during drying [54].

The addition of silica nano-particles causes some changes in the rheological properties of the neat polymer. Nanosilica increases the viscosity values, imparts pseudoplasticity (i.e., the viscosity decreases by increasing the shear rate), and gives thixotropy (i.e., the viscosity increases by increasing the time after shearing) [47]. The increase in viscosity is mainly related to the aggregation of the primary particles [47]. For this reason, the viscosity increases with the nanosilica content, in particular for amounts of nanosilica higher than $2 \mathrm{wt} \%$. Also the choice of the polymer can influence the viscosity. For example, the addition of PDMS to the starting sol can promote a slight increase in viscosity [54].

The incorporation of nanosilica increases the $T_{\mathrm{g}}$ because the nano-sized particles act as crosslinkers as a consequence of the nano-filler-polymer interactions $[47,56,61]$.

\subsection{Nanosilica Hybrids on Stone}

Addition of silica nano-particles at low concentrations $(1-2 \% w / w)$ results in the formation of film on stone with a continuous structure having nano/micro-scale roughness (Figure 7), sometimes exhibiting a two-length-scale hierarchical structure on the surface which is the reason for the superhydrophobic nature of these coatings [39].

The higher the nanosilica consistency the more the possibilities of agglomeration phenomena, which took place for nanosilica content above $2 \%$ [50]; for similar or higher amount of nano-particles, cracks and grooves are observed in some places of the layer $[37,50,57]$ (Figure 8). 

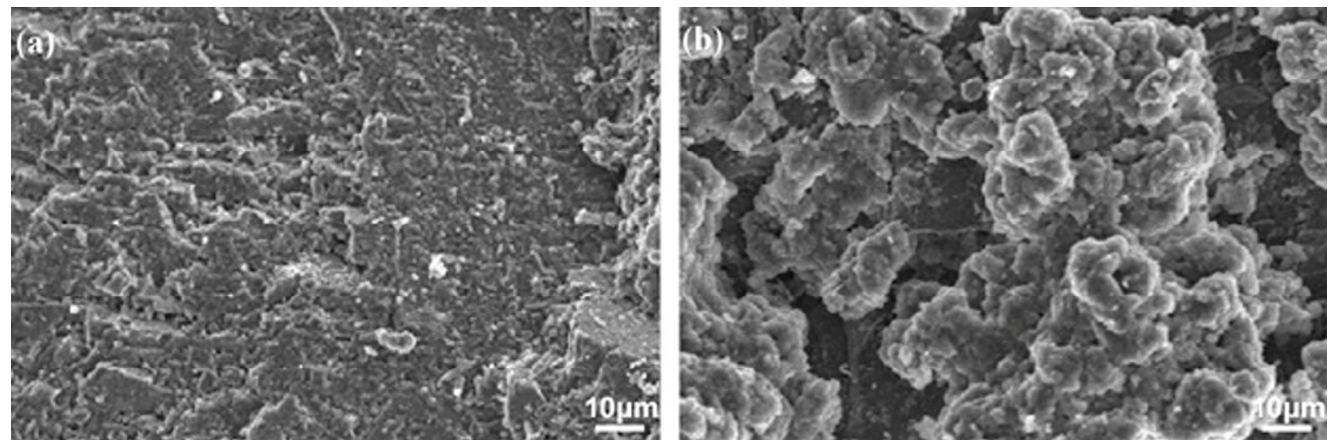

Figure 7. SEM images of (a) untreated marble and (b) marble covered by a superhydrophobic, water repellent composite (the silica/siloxane mass ratio was 0.4 ). Reprinted with permission from [39]. Copyright 2013 John Wiley \& Sons.
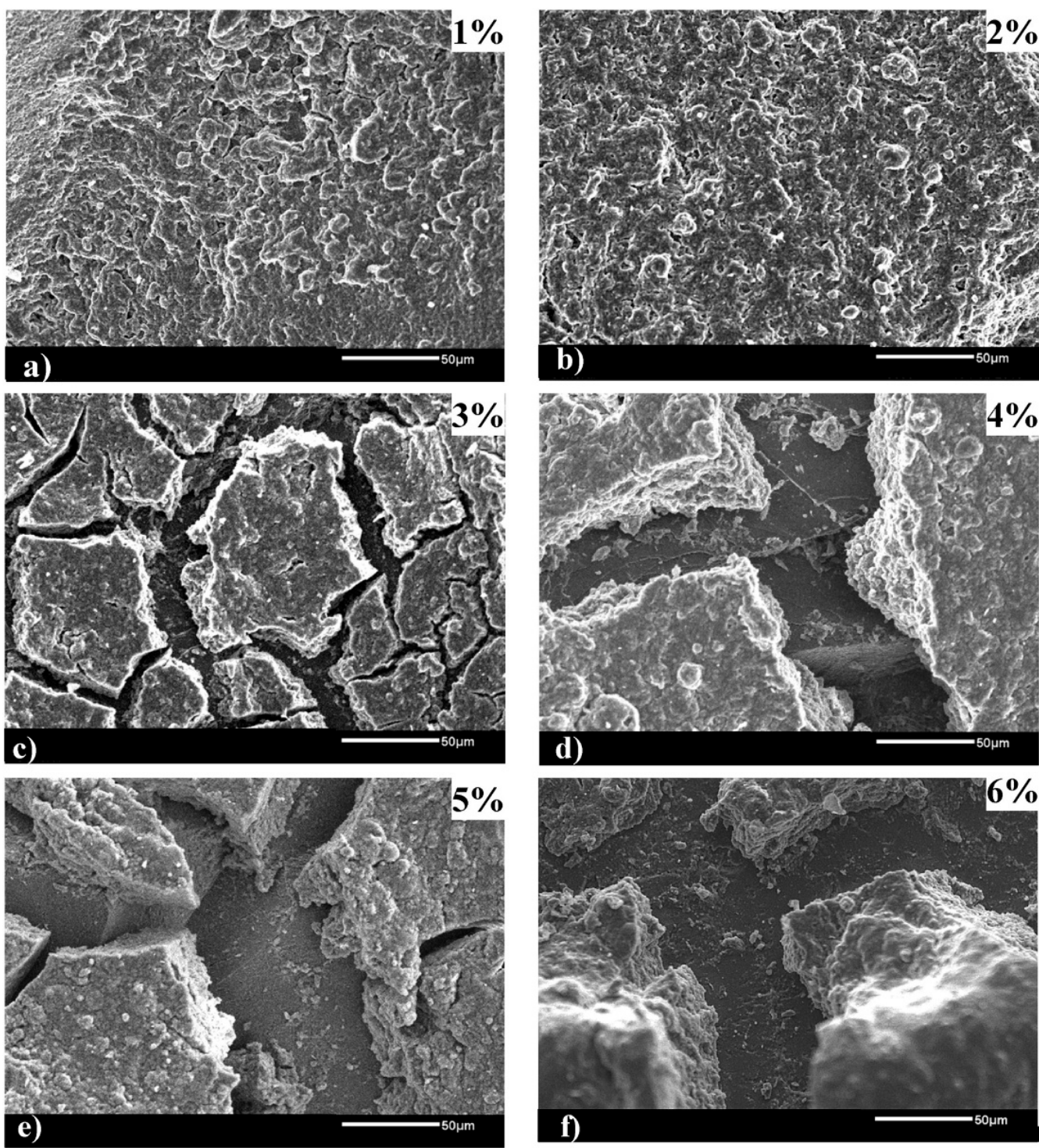

Figure 8. SEM images of marble surfaces coated with siloxane with $\mathrm{SiO}_{2}$ nano-particles at increasing loading (from (a) to (f)). In the upper right corner of each image the nano-particles' concentrations (wt $\%)$ is reported. Reprinted with permission from [37]. Copyright 2016 Elsevier. 
The stone treated with a hybrid obtained by sol-gel process usually exhibits crack-free mesoporous coating on the surface; furthermore, numerous bridges linking together the grains of minerals in the stone can be observed $[41,53,54]$ (Figure 9).

A cracked morphology affects the wettability of the surface. In particular, a strong decrease in contact angle is measured using low surface tension liquids (e.g., oil): drops of these substances sink into the grooves and gradual transition from the non-sticking Cassie-Baxter state to the Wenzel state occurs [37,40]. In addition, the polymer film in-between aggregates is thinner or even disrupted, leading to a decrease in the efficiency of stone protection from water capillary absorption [52].

A significant increase in contact angle is measured and super-hydrophobic behavior is observed with the addition of $1.5 \mathrm{wt} \%$ [50] of nano-particles; sometimes, lower or higher amounts than 1.5\% decreased the contact angle values [50]. It is to take into account that nanosilica alone is typically hydrophilic [62]. The nano-dimensions of silica particles are essential for the super-hydrophobization of the stone surface. In fact, in experimental studies where silica micro-particles (mean diameter $3 \mu \mathrm{m}$ ) in polymer were applied, the super-hydrophobic effect was not achieved and substantially lower static contact angles $\left(120^{\circ}\right.$ instead of $\left.161^{\circ}\right)$ were measured [52].

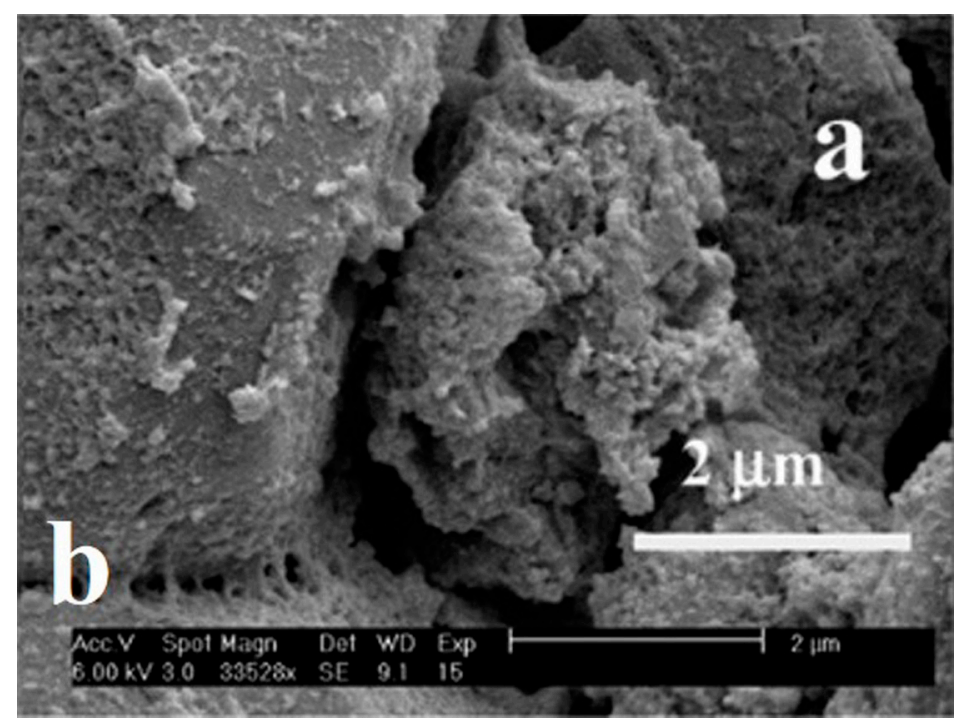

Figure 9. SEM image of a biocalcareous stone treated with an organic-inorganic hybrid (obtained by co-condensation of TEOS and polydimethylsiloxane): (a) coating on the stone grains; (b) nano-material bridges linking together the grains of the stone. Adapted with permission from [54]. Copyright 2010 American Chemical Society.

Contact angle values obtained on surface treated with nanosilica hybrids obtained via sol-gel processes showed a significant enhancement in hydrophobicity, up to super-hydrophobicity. Because the water contact angle cannot be increased beyond $120^{\circ}$ by a purely chemical process on a smooth surface, the high contact angles $\left(>140^{\circ}\right)$ are due to the combined effect of a low surface energy of the polymer and surface roughness [54]. However, in these hybrid materials super-hydrophobicity is not always achieved [53]; this worse behavior is observed where the treatment does not affect surface roughness [43].

Highly water-repellent properties are observed along with of super-hydrophobicity on stone surfaces treated with nanosilica hybrid polymers $[39,52,63]$. This property has been confirmed by the evaluation of the water contact angle hysteresis, which is the most adequate parameter for the assessment of water-repellency. A highly water-repellent surface exhibits a low water contact angle hysteresis $\left(<10^{\circ}\right)$, that is a low difference between the advancing and receding contact angles. In these conditions, a water droplet can move with little applied force and easily rolls off from the surface (Figure 10). 

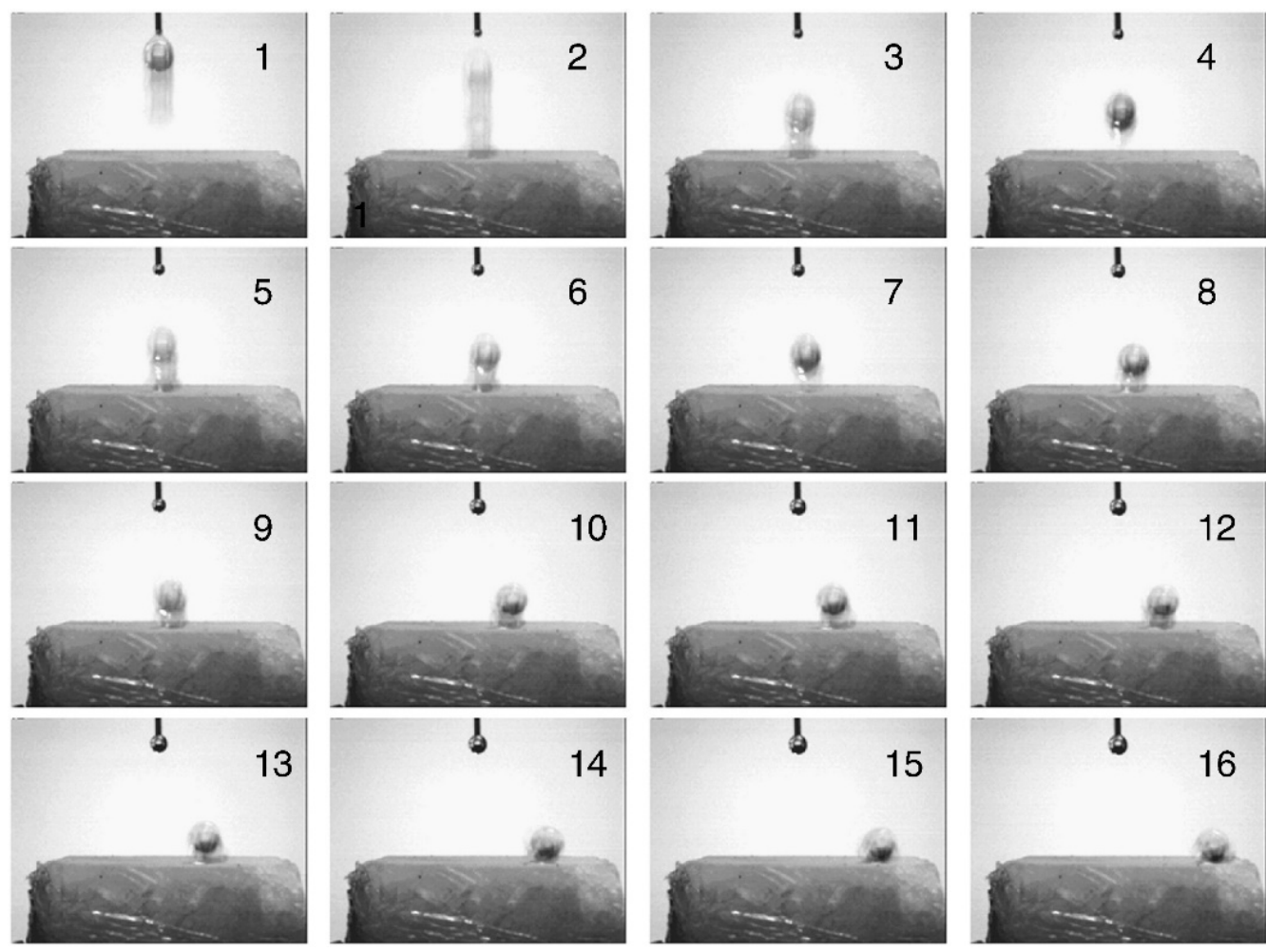

Figure 10. Consecutive images of a water droplet bouncing and rolling off a Pentelic marble treated with siloxane and $1.5 \% w / v$ silica nano-particles. Reprinted with permission from [52]. Copyright 2009 Elsevier.

Although high hydrophobicity (up to water repellence) is observed, water absorption by capillarity is sometime not adequately reduced, partially in contrast with the static contact angle results [38].

The addition of silica nano-particles to the polymer does not significantly reduce the water vapor permeability [51], in particular for porous stone materials [40,64]. Reduction in breathability is measured at high nanosilica concentration, being this reduction associated with the density of the aggregates formed on the surface of the treated stone [52]. Usually, the hybrids obtained via sol-gel do not completely block the porosity, as a consequence the breathability of the stone after the treatments is only slightly reduced [53].

The mechanical characterization has demonstrated a positive influence of the addition of silica nano-particles on impact resistance [47], scratch resistance [61], as well as on surface hardness, because of capacity of coating reorganization and reconstruction during the mechanical tests [51]. Where the products penetrate the stone less deeply, the surface resistance, rather than the compression strength, has been found more appropriate for evaluating the effectiveness of the consolidation for this stone [53].

Nanosilica-based polymer hybrids show a good durability over time, either in accelerated $[55,56]$ or natural aging. In an experimental study, after 5 months of outdoor exposure, water contact angles were reduced, but the treated stone surface remained super-hydrophobic [52]. Amounts of silica nano-particles higher than $2 \%$ allow a suitable resistance in terms of weight loss to freeze-thaw cycles and saline $(\mathrm{NaCl})$ action.

With regard to the durability of these hybrid coatings, release of nano-material by matrix degradation in outdoor uses is a topic of great concern because the polymer binder in a nano-coating can be prone to degradation under the UV radiation of sunlight. Due to the matrix degradation, the nano-particles could be exposed on the coating surface and become more likely susceptible to be released into the environment [42], for example by rain action [49]. The rate of chemical degradation of 
the hybrid polymer can be lower than for the neat polymer, indicating that the nanosilica particles are able to photostabilize the matrix. In the degradation process, silica nano-particles have been observed to accumulate and cluster on the nano-coating surface with increasing UV exposure time (Figure 11); the release take place not randomly but where a critical concentration is reached [42,48].

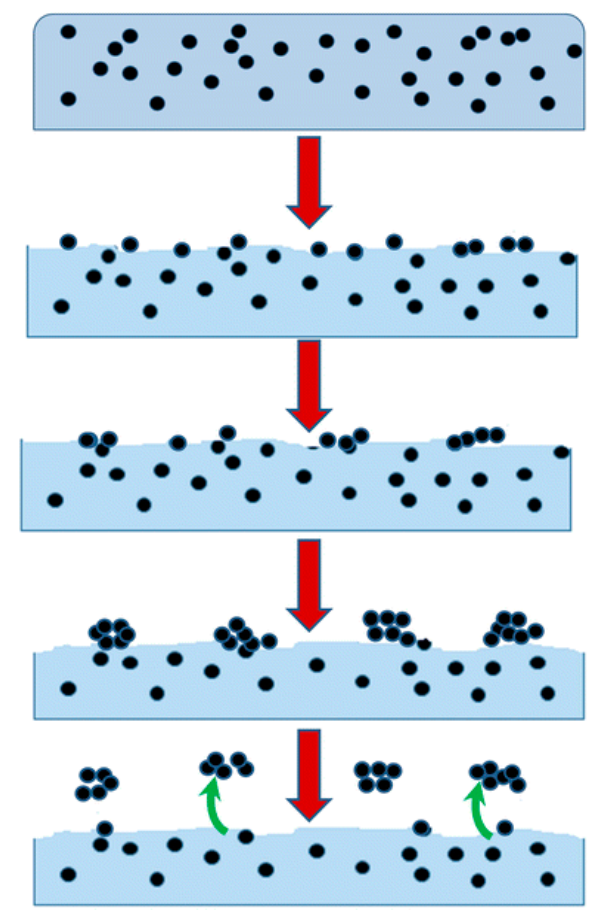

Figure 11. Model for release of nano- $\mathrm{SiO}_{2}$ fillers from a hybrid composite: matrix degradation, formations of particle clusters, and release of particle clusters under increasing UV exposure (from up to bottom). Reprinted with permission from [42]. Copyright 2016 Springer.

\subsection{Nanosilica Hybrids on Wood}

Silica nano-particles have been proposed also as nano-reinforcement in surface coating applications to protect surface of wood substrates.

Addition in UV-photocurable polyurethane acrylate dispersions [65], epoxy acrylates [66,67], acrylic resins [68] has been studied. Photoinitiators, defoamers, surfactants and/or rheological modifiers complete the formulation. Silica nano-particles, added in amounts ranging from $0.5 \%$ to $5 \%$, usually have a particle size of $10-50 \mathrm{~nm}$. Their surface modification with methacrylsilane groups is sometimes suggested [65-67].

Despite the presence of nano-particle aggregates, an improvement of scratch resistance of the applied coatings is measured [69]; an increase of more than $200 \%$ of scratch resistance was reached using only $1 \mathrm{wt} \%$ of nanosilica [65]. The improved scratch resistance is attributed to the reduction of free volume of the hybrid [65]. In fact, as already reported in the previous sections, the addition of nano-particles tends to hinder macromolecular chains mobility at the interface around them. Therefore, in the coating, free volume decreases and the $T_{\mathrm{g}}$ increases.

Reduction of gloss, attributed to an enhancement of surface roughness, and good adhesion to the substrate are also obtained [65]. Adhesion is primarily due to the penetration by capillarity of the liquid coating into the pores of wood and to the subsequent solidification of the polymer. Therefore, a suitable adhesion depends on both porosity properties of the wood substrate and rheological properties of the liquid coating. High amounts of nano-particles increase the viscosity of the applied products because of aggregation effects [66]; as a consequence the adhesion strength is reduced [65]. However, the presence of nano-particle aggregates does not strongly affect the adhesion properties probably because their dimensions are small enough to make it possible the penetration into the pores of wood [65]. 
Super-hydrophobicity is achieved also on wood substrates where a hierarchical structure of the coating with roughness at two length scales is observed. In some cases, super-hydrophobicity is retained also after washing and abrasion test [70].

\section{5. $\mathrm{Nano}_{-} \mathrm{TiO}_{2}$}

$\mathrm{TiO}_{2}$ nano-particles have been extensively applied to obtain multifunctional photocatalytic coatings on architectural stone surfaces [71].

It is well know that materials based on $\mathrm{TiO}_{2}$ nano-particles, thanks to their photocatalytic properties, are able to keep surfaces self-cleaned and to prevent the formation of biofouling. However, for the maintenance of materials in Cultural Heritage, the application of nano- $\mathrm{TiO}_{2}$ dispersion alone seems to be a strategy not effective enough, especially because porous and rough substrates are treated [72]. The nano-particles poorly adhere on the stone surface, tend to penetrate in the porous microstructure, and are easily removed by the mechanical action of wind and rainfall, thus leading to a significant decrease of the effectiveness of the treatment [73]. The application of higher amounts of $\mathrm{TiO}_{2}$ cannot yield better results because the risk of chromatic variations and micro-cracks in the coating is increased. Therefore, the recent approaches are focused to insert these nano-particles inside a polymeric matrix, in order to increase the surface roughness without changing the main characteristics of the material, such as permeability and transparency, and the substrate morphology [72,74]. By adopting an appropriate procedure, it is possible to harmonize the characteristics of the $\mathrm{TiO}_{2}$ and the properties of polymer materials, obtaining nano-structured inorganic-organic hybrid coatings that protect against water, as evidenced by high contact angles, and photodegrade pollutants when illuminated by sunlight. Among the three crystalline forms of titanium dioxide: rutile, brookite and anatase, the last one is generally considered the most active photocatalyst.

\subsection{Preparation and Properties of $\mathrm{Nano}-\mathrm{TiO}_{2}$ Hybrids}

Titanium dioxide nano-particles have been added to polymer based on acrylic [75-77], siloxanes [74,77], fluorinated polymers [74,75,78,79], polyurethanes [80]. Organic solvent [73,75] or aqueous suspension [73-76] can be employed. The used $\mathrm{TiO}_{2}$ nano-particles, usually having particle mean diameter of about $20-50 \mathrm{~nm}$, are commercially available products or are synthesized through sol-gel method by hydrolysis of titanium isopropoxide in acid condition [14]. In the latter case, a suitable amount of a surfactant is added to the sol in order to disperse the nano-particles and avoid aggregation processes. In fact, this method allows the preparation of a product with a small percentage of brookite and the anatase phase predominant (evaluated by XRD and Raman); in addition, the crystallites size of anatase particles, estimated by TEM, can be in the 4-6 $\mathrm{nm}$ range [81].

The process of mixing of polymer and $\mathrm{TiO}_{2}$ can be obtained by stirring or sonication [82]. However, the low chemical affinity between organic polymers and inorganic particles makes the mechanical methods of dispersion insufficient, while a chemical approach is usually more effective [83]. The addition of coupling agents (tetraisopropoxide or TEOS) to the film formulation [83] or nano-particles' functionalization [81] are the preferred methods.

The addition of $\mathrm{TiO}_{2}$ nano-particles can induce increases in $T_{\mathrm{g}}$ mainly because the inorganic nano-phase reduces the mobility of the polymer chain segments [80]. This aspect can be particularly important for applications in the field of Cultural Heritage, where coatings with close or lower the room temperature are too much soft for working and moreover are inclined to pick up dust and dirty from the environment.

\subsection{Nano-TiO $\mathrm{O}_{2}$ Hybrids on Stone}

EDS investigations well follow the penetration depth of treatments on stone, due to the fact that titanium is not a component of most stone materials (in particular, marbles and calcarenites) [75]. Although it can be assumed that the polymer spreads at least as much as $\mathrm{TiO}_{2}$, sometimes a lower 
penetration of the smaller nano-particles has been found. This leads to a higher nano-particles/binder ratio on the surface, which improves the efficacy of $\mathrm{TiO}_{2}$ [75].

It is worth noting that the penetration depth of $\mathrm{TiO}_{2}$ does not necessarily matches that of the polymer, since the size of these two components are different. The result mainly depends on the porosity of the substrate; the greater the porosity, the higher the penetration depth. In highly porous stone, $\mathrm{TiO}_{2}$ hybrid polymers have been found up to $3 \mathrm{~mm}$ under the surface $[75,76]$.

A deeper penetration is useless for the coating performance in terms of hydrophobicity, but can slightly inhibit the photocatalytic properties of the $\mathrm{TiO}_{2}$ nano-particles on the surface. Conversely, a certain level of penetration can assure an adequate anchoring of the coating to the stone, which assures implementation of hydrophobicity and durability [75]. Additionally, greater roughness and porosity promote adhesion of the polymer to the substrate [75].

The presence of low amounts of $\mathrm{TiO}_{2}$ in nano-composites are difficult to detect by FTIR [73]. The appearance of an absorption peak at about $700 \mathrm{~cm}^{-1}$ is related to Ti-O stretching; in addition, the increase of the $\mathrm{OH}$ stretching band (in the range 3400 and $3000 \mathrm{~cm}^{-1}$ ) and $\mathrm{OH}$ bending signal (around $1630 \mathrm{~cm}^{-1}$ ) is due to emisorbed hydroxyls groups bonded to $\mathrm{TiO}_{2}$ [74]. In silicon-based hybrids also the slight broadening of the peak at about $950 \mathrm{~cm}^{-1}$ is observed, due to the formation of $\mathrm{Si}-\mathrm{O}-\mathrm{Ti}$ interactions between the polymer matrix and the nano-particles [74].

As SEM and TEM observations highlighted, no aggregation of nano-particles occurs in polysiloxanes-based treatments [73], even for high $\mathrm{TiO}_{2}$ concentrations (44 wt \%) [74]. $\mathrm{TiO}_{2}$ nano-particles tend to aggregate in micrometric clusters in fluoropolymer-based nano-composite, instead, due to the low affinity between nano-particles and the water dispersion of fluoropolymers [74].

Where the coating induces or enhances the roughness, often due to the nano-particles' disposition, a different aesthetic appearance of the surface can be observed [75]. In addition, it must be taken into account that $\mathrm{TiO}_{2}$ nano-particles are usually white in color, so that they can produce a lower color variation on whitish stone, such as marbles [75]. Furthermore, this whitening effect can have a beneficial influence, balancing the yellow color of some polymer [73,74]. The capability of producing transparent polymer coatings modified with $\mathrm{TiO}_{2}$ nano-particles depends on the particle dimensions and on their effective dispersion in the polymer medium. Particle size lower than $50 \mathrm{~nm}$ allows that light is transmitted and the final coating is transparent [83].

When $\mathrm{TiO}_{2}$ nano-particles and the hydrophobic polymer are mixed together, the final water contact angles remarkably increase as the $\mathrm{TiO}_{2}$ amount increase in the hybrid formulation [74,78]. Also water repellency can be achieved, with water drops bouncing and rolling off the treated surface [84].

An increase of nano-roughness of the treated surfaces, with the reduction of the surface free energy, increases by increasing the $\mathrm{TiO}_{2}$ concentration and higher values are related to the reduction in wettability of the treated surface [74]. The changes in nano-roughness are more relevant on stone materials characterized by low roughness values, such as marbles, while this parameter is slightly affected where the original roughness is already high [73]. In this latter case, the distribution of the hydrophobic coating than the presence of nano-particles affects the wettability of the substrate.

A high hydrophobicity of treated stone surfaces has been measured by using rod-shaped $\mathrm{TiO}_{2}$ nano-crystals in oleic acid [85]. In this study, surprisingly, in the absence of $\mathrm{TiO}_{2}$ a hydrophilic behavior was observed. This result has been explained considering that molecules of oleic acid, when not coordinated to the $\mathrm{TiO}_{2}$, can randomly orient on the stone sample. The $\mathrm{TiO}_{2}$ nano-rods are able to coordinate the molecules of oleic acid that expose their hydrophobic moieties toward the solid-air interface, thus decreasing the wettability of the stone surface.

Capillary water absorption is usually positively influenced in presence of $\mathrm{TiO}_{2}$ nano-particles $[73,74,76]$. However, this parameter can be found in disagreement with contact angle measurements performed on the same specimens [75,79], even if low amounts of absorbed water are expected to be associated with high contact angle values. However, the results provided by the contact angle are related to an "instantaneous" hydrophobicity and take into consideration only the interface 
drop-surface. Conversely, the absorption test verifies the long-term water resistance measuring the quantity of water absorbed over the entire area of the sample [75].

It is worth noting that those treatments that show a better penetration exhibit a better hydrophobicity at long-term [75], but a worse behavior in terms of photocatalytic activity (biocidal effect and stain discoloration) [76].

Different behaviors in terms of water vapor permeability have been observed in the presence of $\mathrm{TiO}_{2}$ nano-particles within the polymer. In some cases, the use of a hybrid have significantly reduced the vapor permeability (up to 60\% [73]), indicating that the product accumulates into the pores of the stone, occluding them in a large extent. No (or very low) influence has been also noticed, even in very compact stone materials [73], measuring values comparable using either the hybrids or the polymer alone [79]. In other cases, unexpected increase in water vapor permeability have been found after the treatment [85]. This latter result is common in highly hydrophilic surfaces [86] and has been explained as related to a lower condensation phenomenon on the hydrophobic pore walls. Consequently, the diffusion rate of water vapor through hydrophobic pores is higher than the diffusion rate through hydrophilic pores. This result is neutralized when the applied hydrophobic product tends to fill the pores rather than coating them as a thin layer $[73,87]$. The consequent reduction in pores' dimensions slows down (or inhibits) the vapor flow [88]. This latter effect is dominant and a permeability decrease is observed as overall result [73].

Stone surfaces treated with the nano- $\mathrm{TiO}_{2}$ polymer composites show higher photocatalytic activity under light irradiation in terms of organic dye discoloration (rhodamine B [73,74,79], methylene blue [76,81], methyl orange [80], methyl red [85]) in comparison to the untreated ones or to the polymer coating alone $[74,79]$. In those cases, it is evident that the $\mathrm{TiO}_{2}$ nano-particles accelerate the oxidative degradation of the colorant. The amount of $\mathrm{TiO}_{2}$ nano-filler on the surface is the main factor affecting the photodegradation efficacy [76]. Also where a defective surface coverage of the substrate, with aggregation of the nano-particles, has been observed, poor performance in photoactivity and inferior colorant discoloration are obtained [74]. This capability of self-cleaning from stain has been applied for the discoloration of graffiti drawn on modified coatings [83].

Photocathalytic nano- $\mathrm{TiO}_{2}$ under light irradiation also exhibit super-hydrophilicity, which can interfere with the hydrophobicity induced by the polymer. In addition, the polymer degradation can take place, thus leading to a significant alteration of the original features.

Surfaces coated with acrylic/nano- $\mathrm{TiO}_{2}$ hybrid usually reach lower performance and exhibit higher wettability because of the photo-degradation the acrylic component under UV radiation $[75,76]$, while improved performances and durability have been observed using fluorine-based polymers [75]. Actually, the UV exposure of nano- $\mathrm{TiO}_{2}$ fluorinated hybrids can yield a decrease of the contact angles. However, after the removal of any light source, the original values are recovered over time [81]. These results have been explained as due to the presence of an unnoticed film of water induced by the super-hydrophilicity of $\mathrm{TiO}_{2}$ nano-particles, which remained on the stone surface for an extended time after its exposure to UV radiation, rather than to the degradation of the polymeric film [79].

The application of hybrid coatings have produced a better protection against salts formation, in comparison to that obtained applying the polymer, after exposure tests in a typical urban polluted environment [78] in wintertime. In particular the efficiency of the hybrid application is evident in decreasing concentration of sulphate and chloride ions [78].

The option to prevent the bio-colonization of restored surfaces is of high importance and has gained attention due to the fact that products used for conservation purposes may serve themselves as nutrient and thus support the biological colonization of the restored surfaces [82]. In this field, $\mathrm{TiO}_{2}$ has been extensively used as biocide against various microorganisms (bacteria, fungi and viruses) due to its broad-spectrum antibiosis, its chemical stability, non-toxicity, high photo-reactivity, and cheapness [77,82]. Treatments with nano- $\mathrm{TiO}_{2}$ hybrids are able to induce inhibition in biological growth. Although bioreceptivity of stone materials is highly variable and strongly depends on surface roughness, initial porosity and mineralogical characteristics, the positive effect has been observed on 
dissimilar lithotypes [76], while greater amounts of nano-powder have not improved the efficiency as biocidal agent.

\subsection{Nano-TiO $\mathrm{O}_{2}$ Hybrids on Wood}

During outdoor exposure, the initially appealing color of the wood surface changes very rapidly after a quite short period due to photo-oxidation processes, increase in hydrophilicity, erosion, and microbiological attack. Despite the fact that the loss of mechanical properties of weathered wood is limited to the upper cell rows and therefore negligible for construction purposes, the optical appearance is strongly altered [89]. The polymer lignin undergo bond cleavage and hydrogen abstraction, resulting in the formation of radicals or peroxides easily decomposed to produce chromophoric groups (such as carbonyl and carboxyl groups), and directly responsible for the wood yellowing/darkening [90].

The addition of $\mathrm{TiO}_{2}$ nano-particles to coatings for wood such as UV-blocking agents is an extensive practice. From the different polymorphs present in $\mathrm{TiO}_{2}$ nano-particles, rutile offers greater effectiveness as a stabilizer of photo-oxidation of polymers [91,92]. Rutile is an excellent candidate for UV protection because of its high refractive index $(n=2.7)$, wide band gap $(3.05 \mathrm{eV})$, ability to scatter solar radiation and absorb UV radiation.

In applications for wood protection, many positive effects have been observed: the cellular microstructures of wood are easily and well coated by the nano-particles [93]; good anchoring takes place through interaction of $\mathrm{TiO}_{2}$ particles with hemicellulose and lignin [94]; pronounced hydrophobicity $[93,94]$ and reduction of fungi growth $[95,96]$ are found. However, $\mathrm{TiO}_{2}$ for UV protection of wood difficult work effectively if used alone or if the applied coating does not achieve a suitable thickness $[97,98]$. To improve the performances, the addition of a dopant (e.g., Ce [89]) or an organic commercial UV adsorber [98], as well as the preparation of an organic-inorganic hybrid have been employed.

Hybrids based on acrylic and methacrylic monomers have been successfully applied for protection of wood, where contradictory requirements have to be satisfied. In such application, the coating must tolerate the expansion and contraction of wood, influenced by humidity and temperature, it must be hard enough to withstand mechanical or chemical attack on the surface and stress at the interface due to dimensional changes of wood $[89,91]$.

The $\mathrm{TiO}_{2}$ nano-particles in the hybrid show a tendency toward agglomeration, therefore the distribution of nano-particles was often not homogenous throughout the matrix. Adhesion and water absorption were not significantly affected by the addition of $\mathrm{TiO}_{2}$. Indeed, the addition of $\mathrm{TiO}_{2}$ favors the absorption of a great amount of UV rays, thus increasing durability. This behavior was evident in wood samples subjected to either artificial or natural weathering, where degradation and color changes were observed $[7,91,99]$.

\section{6. $\mathrm{SiO}_{2}-\mathrm{TiO}_{2}$ Based Hybrids}

In a more recent approach, $\mathrm{TiO}_{2}$ is mixed with $\mathrm{SiO}_{2}$ to obtain nano-particles for hybrid coatings.

Hybrids based on $\mathrm{SiO}_{2}-\mathrm{TiO}_{2}$ nano-particles can be obtained by mixing Ti-alkoxide and Si-alkoxide precursors, by grafting pre-synthesized silica with Ti-alkoxide or by mixing pre-formed titania colloidal nano-particles in a Si-alkoxide sol [100]. The addition of the polymer is the subsequent step, in general by using ultrasonic bath [101].

Acrylic polymers have been used as the organic component [102]. The employ of polydimethylsiloxane (PDMS) has provided hydrophobic properties and enhancement of toughness and flexibility of the silica network, thus preventing the gel from cracking during drying $[103,104]$.

Oxalic acid has been used in order to catalyze the hydrolysis of TEOS, as well as both to control the grain growth of $\mathrm{TiO}_{2}$ and the solvent drying, and to create a $\mathrm{pH}$ environment that prevents the particle $\mathrm{TiO}_{2}$ agglomeration [103]. In this case, a transparent and cracked-free film derived from the sol-gel hybrid synthesized material is observed by SEM examinations. From TEM investigations, particle size distribution presents lower values at lower $\mathrm{pH}$ levels [104]. The addition of oxalic acid seems play 
a valuable role. In fact, in absence of this substance, coatings exhibiting cracks, a non-homogeneous distribution and aggregation of the $\mathrm{TiO}_{2}$ nano-particles have been obtained [101]. These features negatively affect the performance of the treated surface, in particular the water absorption by capillarity.

To prevent cracking of the coating and to enhance photocatalytic activity by creating a mesoporous nano-composite, $\mathrm{TiO}_{2}$ colloidal particles are added in the presence of a surfactant (n-octylamine [105]) to a silica oligomer, which is capable of adhering well to the stone. The employment of a nonionic surfactant allows avoiding additional steps (e.g., calcinations), which in Cultural Heritage field must be avoided because the coating will normally have to be applied in situ, on the external surface of a building stone material.

It has been demonstrated that n-octylamine, creating a mesoporous structure, efficiently reduces the capillary pressure and crack-free, therefore homogeneous, and coarser coatings on the stone surface are obtained $[105,106]$. In addition, favoring the interaction between the siloxane and the apolar carbonate stone, n-octylamine has enhanced the consolidant effectiveness of siloxane, while it is known that silicon-based products are less effective in pure carbonate stones [106]. However, color changes have been observed using n-octylamine, which may imparts a slightly yellowish color to the treated stone materials. This disadvantage is progressively reduced as the $\mathrm{TiO}_{2}$ content is raised, since these particles have a whitening effect [105].

In the $\mathrm{SiO}_{2}-\mathrm{TiO}_{2}$ hybrids, the $\mathrm{TiO}_{2}$ nano-particles promote a significant increase in viscosity [100]. An unexpected trend, in which the increase in particle size seems to produce lower viscosity, has been also observed. This behavior has been attributed to the agglomeration of $\mathrm{TiO}_{2}$ nano-particles. In fact, aggregation takes place in order to reduce the high surface energy of the particles, which is more significant for the lowest average particle size.

The polymerization of the hybrid material can be assessed by observing changes in several absorptions in the FTIR spectra [103]. The incorporation of $\mathrm{TiO}_{2}$ to the silica network is revealed by the creation of $\mathrm{Si}-\mathrm{O}-\mathrm{Ti}$ bonds, showing signals located in the spectral range of $920-950 \mathrm{~cm}^{-1}$. The absence of the absorption of the Ti-O bonds of pure $\mathrm{TiO}_{2}$ around $550 \mathrm{~cm}^{-1}$ can further support the realization of a proper hybrid structure [103].

$\mathrm{TiO}_{2}$ nano-particles integrated into a $\mathrm{SiO}_{2}$-based matrix, which is able of adhering firmly to the stone, provide long-term wear resistance, improve surface mechanical resistance, and salt crystallization degradation, along with self-cleaning and hydrophobic properties of the treated stone material $[99,104,105]$.

The organic dye discoloration (methylene blue [103], methyl orange [104]) and the biofilm removal on treated stone samples support the self-cleaning properties of the coatings.

The organic component reduces the surface energy, producing hydrophobicity, as it is proved by the water capillary coefficient and contact angle measurements [103]; higher contact angle values are due to a higher surface roughness induced by the nano-particles in the hybrid [104]. Finally, the variation of the water vapor permeability and color parameters ranged within acceptable limits $[103,104]$.

An additional valuable advantage in using $\mathrm{SiO}_{2}-\mathrm{TiO}_{2}$ hybrids has been recognized in the decreased release of nano-particles in the environment. This undoubtedly represents a positive response in terms of reduction of potential hazard of this class of materials [107].

\section{Other Nano-Particles for Hybrids}

In addition to the nano-composites described in the previous sections, other hybrids based on nano-particles have been proposed for applications on materials of the Cultural Heritage. The most common products are: nano-calcite in acrylic matrices $[108,109]$, chemically more compatible with carbonate stones, as an alternative to silica-based treatments; nano-silver particles [110] or $\mathrm{Cu}$-nano-particles [111] in acrylate/methacrylate polymers, to impart antimicrobial properties; silica-calcium oxalate hybrids as consolidants [112]; nano-hydroxyapatite in silane/siloxane matrices 
for stone consolidation and protection [87,113]; cellulose nano-crystals in UV-light curable in siloxane-modified methacrylic resin for wood protection [6].

Although less widely employed, the investigated products exhibit good compatibility with the stone/wood substrates, improved surface properties in terms of hydrophobicity/water absorption and strengthening of the stone material, as well as resistance to weathering.

\section{Conclusions}

Hybrid nano-composites, being carefully selected the nano-particles, the polymer matrix and the processes of preparation, are able to impart interesting properties and suitable performances to the treated stone/wood substrates.

These novel nano-materials have been deeply investigated and applied for conservative purposes in the field of the Cultural Heritage preservation. However, there is currently little known about their efficacy, behavior, and durability under actual conditions. In this regard, thorough studies and experimental activity should be performed directly on real surfaces. In addition, risks for human health and environment from the use of the new nano-materials for materials' preservation should be a primary concern in future research. Finally, in the literature thus reviewed, little or very low attention has been paid to economic considerations: the cost/performance ratio should be always taken into account and put in relation with the value of the artwork/structure to be preserved.

Funding: This research received no external funding.

Conflicts of Interest: The authors declare no conflict of interest.

\section{References}

1. Doehne, E.; Price, C.A. Stone Conservation: An Overview of Current Research, 2nd ed.; Getty Conservation Institute: Los Angeles, CA, USA, 2010.

2. Sierra-Fernandez, A.; Gomez-Villalba, L.S.; Rabanal, M.E.; Fort, R. New nanomaterials for applications in conservation and restoration of stony materials: A review. Mater. Constr. 2017, 67, 107. [CrossRef]

3. Cao, Y.; Salvini, A.; Camaiti, M. Oligoamide grafted with perfluoropolyether blocks: A potential protective coating for stone materials. Prog. Org. Coat. 2017, 111, 164-174. [CrossRef]

4. Corcione, C.E.; Manno, R.; Frigione, M. Sunlight curable boehmite/siloxane-modified methacrylic nano-composites: An innovative solution for the protection of carbonate stones. Prog. Org. Coat. 2016, 97, 222-232. [CrossRef]

5. Horie, C.V. Materials for Conservation: Organic Consolidants, Adhesives and Coatings; Routledge: London, UK, 2010.

6. Cataldi, A.; Corcione, C.E.; Frigione, M.; Pegoretti, A. Photocurable resin/nanocellulose composite coatings for wood protection. Prog. Org. Coat. 2017, 106, 128-136. [CrossRef]

7. Fufa, S.M.; Jelle, B.P.; Hovde, P.J.; Rørvik, P.M. Coated wooden claddings and the influence of nanoparticles on the weathering performance. Prog. Org. Coat. 2012, 75, 72-78. [CrossRef]

8. Turri, S.; Alborghetti, L.; Levi, M. Formulation and properties of a model two-component nanocomposite coating from organophilic nanoclays. J. Polym. Res. 2008, 15, 365-372. [CrossRef]

9. Landry, V.; Blanchet, P.; Riedl, B. Mechanical and optical properties of clay-based nanocomposites coatings for wood flooring. Prog. Org. Coat. 2010, 67, 381-388. [CrossRef]

10. Yu, Y.-H.; Lin, C.-Y.; Yeh, J.-M.; Lin, W.-H. Preparation and properties of poly(vinyl alcohol)-clay nanocomposite materials. Polymer 2003, 44, 3553-3560. [CrossRef]

11. Corcione, C.E.; Frigione, M. Characterization of nanocomposites by thermal analysis. Materials 2012, 5, 2960-2980. [CrossRef]

12. Decker, C.; Keller, L.; Zahouily, K.; Benfarhi, S. Synthesis of nanocomposite polymers by UV-radiation curing. Polym. Blends Compos. Hybrid Polym. Mater. 2005, 46, 6640-6648. [CrossRef]

13. Bellisario, D.; Quadrini, F.; Santo, L. Nano-clay filled polyester coatings. Prog. Org. Coat. 2013, 76, 1863-1868. [CrossRef]

14. Corcione, C.E.; Frigione, M. UV-cured polymer-boehmite nanocomposite as protective coating for wood elements. Prog. Org. Coat. 2012, 74, 781-787. [CrossRef] 
15. Ray, S.S.; Okamoto, M. Polymer/layered silicate nanocomposites: A review from preparation to processing. Prog. Polym. Sci. 2003, 28, 1539-1641. [CrossRef]

16. Bhattacharyya, K.G.; Gupta, S.S. Adsorption of a few heavy metals on natural and modified kaolinite and montmorillonite: A review. Adv. Colloid Interface Sci. 2008, 140, 114-131. [CrossRef] [PubMed]

17. Alexandre, M.; Dubois, P. Polymer-layered silicate nanocomposites: Preparation, properties and uses of a new class of materials. Mater. Sci. Eng. R Rep. 2000, 28, 1-63. [CrossRef]

18. Wang, S.; Zhang, Y.; Ren, W.; Zhang, Y.; Lin, H. Morphology, mechanical and optical properties of transparent BR/clay nanocomposites. Polym. Test. 2005, 24, 766-774. [CrossRef]

19. Nkeuwa, W.N.; Riedl, B.; Landry, V. UV-cured clay/based nanocomposite topcoats for wood furniture. Part II: Dynamic viscoelastic behavior and effect of relative humidity on the mechanical properties. Prog. Org. Coat. 2014, 77, 12-23. [CrossRef]

20. D'Arienzo, L.; Scarfato, P.; Incarnato, L. New polymeric nanocomposites for improving the protective and consolidating efficiency of tuff stone. J. Cult. Herit. 2008, 9, 253-260. [CrossRef]

21. Licchelli, M.; Malagodi, M.; Weththimuni, M.; Zanchi, C. Anti-graffiti nanocomposite materials for surface protection of a very porous stone. Appl. Phys. A 2014, 116, 1525-1539. [CrossRef]

22. Ocak, Y.; Sofuoglu, A.; Tihminlioglu, F.; Böke, H. Sustainable bio-nano composite coatings for the protection of marble surfaces. J. Cult. Herit. 2015, 16, 299-306. [CrossRef]

23. Nkeuwa, W.N.; Riedl, B.; Landry, V. UV-cured clay/based nanocomposite topcoats for wood furniture: Part I: Morphological study, water vapor transmission rate and optical clarity. Prog. Org. Coat. 2014, 77, 1-11. [CrossRef]

24. Fufa, S.M.; Jelle, B.P.; Hovde, P.J. Effects of $\mathrm{TiO}_{2}$ and clay nanoparticles loading on weathering performance of coated wood. Prog. Org. Coat. 2013, 76, 1425-1429. [CrossRef]

25. Fufa, S.M.; Jelle, B.P.; Hovde, P.J. Weathering performance of spruce coated with water based acrylic paint modified with $\mathrm{TiO}_{2}$ and clay nanoparticles. Prog. Org. Coat. 2013, 76, 1543-1548. [CrossRef]

26. Karger-Kocsis, J.; Lendvai, L. Polymer/boehmite nanocomposites: A review. J. Appl. Polym. Sci. 2017, 135, 45573. [CrossRef]

27. Corcione, C.E.; Frigione, M. Cure kinetics and physical characterization of epoxy/modified boehmite nanocomposites. J. Adhes. Sci. Technol. 2017, 31, 645-662. [CrossRef]

28. Corcione, C.E.; Frigione, M.; Maffezzoli, A.; Malucelli, G. Photo-DSC and real time-FT-IR kinetic study of a UV curable epoxy resin containing o-Boehmites. Eur. Polym. J. 2008, 44, 2010-2023. [CrossRef]

29. Corcione, C.E.; Frigione, M.; Acierno, D. Rheological characterization of UV-curable epoxy systems: Effects of o-Boehmite nanofillers and a hyperbranched polymeric modifier. J. Appl. Polym. Sci. 2009, 112, 1302-1310. [CrossRef]

30. Corcione, C.E.; Frigione, M. Surface characterization of novel hydrophobic UV-curable siloxane-modified methacrylate/boehmite nanocomposites. Polym. Compos. 2013, 34, 1546-1552. [CrossRef]

31. Corcione, C.E.; Manno, R.; Frigione, M. Sunlight-curable boehmite/siloxane-modified methacrylic based nanocomposites as insulating coatings for stone substrates. Prog. Org. Coat. 2016, 95, 107-119. [CrossRef]

32. Corcione, C.E.; De Simone, N.; Santarelli, M.L.; Frigione, M. Protective properties and durability characteristics of experimental and commercial organic coatings for the preservation of porous stone. Prog. Org. Coat. 2017, 103, 193-203. [CrossRef]

33. Corcione, C.E.; Frigione, M. Novel UV-cured nanocomposite used for the protection of walnut wood artworks. Wood Res. 2014, 59, 229-244.

34. Cappelletti, G.; Fermo, P. Hydrophobic and superhydrophobic coatings for limestone and marble conservation. In Smart Composite Coatings and Membranes; Montemor, M.F., Ed.; Elsevier Inc.: Amsterdam, The Netherlands, 2016; pp. 421-452.

35. Chattopadhyay, D.K.; Raju, K.V.S.N. Structural engineering of polyurethane coatings for high performance applications. Prog. Polym. Sci. Oxf. 2007, 32, 352-418. [CrossRef]

36. Ruffolo, S.A.; La Russa, M.F.; Ricca, M.; Belfiore, C.M.; Macchia, A.; Comite, V.; Pezzino, A.; Crisci, G.M. New insights on the consolidation of salt weathered limestone: The case study of Modica stone. Bull. Eng. Geol. Environ. 2017, 76, 11-20. [CrossRef]

37. Aslanidou, D.; Karapanagiotis, I.; Panayiotou, C. Tuning the wetting properties of siloxane-nanoparticle coatings to induce superhydrophobicity and superoleophobicity for stone protection. Mater. Des. 2016, 108, 736-744. [CrossRef] 
38. De Ferri, L.; Lottici, P.P.; Lorenzi, A.; Montenero, A.; Salvioli-Mariani, E. Study of silica nanoparticles-Polysiloxane hydrophobic treatments for stone-based monument protection. J. Cult. Herit. 2011, 12, 356-363. [CrossRef]

39. Chatzigrigoriou, A.; Manoudis, P.N.; Karapanagiotis, I. Fabrication of water repellent coatings using waterborne resins for the protection of the cultural heritage. Macromol. Symp. 2013, 331-332, 158-165. [CrossRef]

40. Aslanidou, D.; Karapanagiotis, I.; Lampakis, D. Waterborne superhydrophobic and superoleophobic coatings for the protection of marble and sandstone. Materials 2018, 11, 585. [CrossRef] [PubMed]

41. Facio, D.S.; Ordoñez, J.A.; Almoraima Gil, M.L.; Carrascosa, L.A.M.; Mosquera, M.J. New consolidant-hydrophobic treatment by combining $\mathrm{SiO}_{2}$ composite and fluorinated alkoxysilane: Application on decayed biocalcareous stone from an 18th century cathedral. Coatings 2018, 8, 170. [CrossRef]

42. Jacobs, D.S.; Huang, S.-R.; Cheng, Y.-L.; Rabb, S.A.; Gorham, J.M.; Krommenhoek, P.J.; Yu, L.L.; Nguyen, T.; Sung, L. Surface degradation and nanoparticle release of a commercial nanosilica/polyurethane coating under UV exposure. J. Coat. Technol. Res. 2016, 13, 735-751. [CrossRef] [PubMed]

43. Pagliolico, S.L.; Ozzello, E.D.; Sassi, G.; Bongiovanni, R. Characterization of a hybrid nano-silica waterborne polyurethane coating for clay bricks. J. Coat. Technol. Res. 2016, 13, 267-276. [CrossRef]

44. Sow, C.; Riedl, B.; Blanchet, P. Kinetic studies of UV-waterborne nanocomposite formulations with nanoalumina and nanosilica. Prog. Org. Coat. 2010, 67, 188-194. [CrossRef]

45. Corcione, C.E.; Striani, R.; Frigione, M. Organic-inorganic UV-cured methacrylic-based hybrids as protective coatings for different substrates. Prog. Org. Coat. 2014, 77, 1117-1125. [CrossRef]

46. Corcione, C.E.; Striani, R.; Capone, C.; Molfetta, M.; Vendetta, S.; Frigione, M. Preliminary study of the application of a novel hydrophobic photo-polymerizable nano-structured coating on concrete substrates. Prog. Org. Coat. 2018, 121, 182-189. [CrossRef]

47. Morote-Martínez, V.; Pascual-Sánchez, V.; Martín-Martínez, J.M. Improvement in mechanical and structural integrity of natural stone by applying unsaturated polyester resin-nanosilica hybrid thin coating. Eur. Polym. J. 2008, 44, 3146-3155. [CrossRef]

48. Nguyen, T.; Pellegrin, B.; Bernard, C.; Rabb, S.; Stuztman, P.; Gorham, J.M.; Gu, X.; Yu, L.L.; Chin, J.W. Characterization of surface accumulation and release of nanosilica during irradiation of polymer nanocomposites by ultraviolet light. J. Nanosci. Nanotechnol. 2012, 12, 6202-6215. [CrossRef] [PubMed]

49. Sung, L.; Stanley, D.; Gorham, J.M.; Rabb, S.; Gu, X.; Yu, L.L.; Nguyen, T. A quantitative study of nanoparticle release from nanocoatings exposed to UV radiation. J. Coat. Technol. Res. 2014, 12, 121-135. [CrossRef]

50. Stefanidou, M.; Matziaris, K.; Karagiannis, G. Hydrophobization by means of nanotechnology on greek sandstones used as building facades. Geosci. Switz. 2013, 3, 30-45. [CrossRef]

51. Fic, S.; Szewczak, A.; Barnat-Hunek, D.; Lagód, G. Processes of fatigue destruction in nanopolymer-hydrophobised ceramic bricks. Materials 2017, 10, 44. [CrossRef] [PubMed]

52. Manoudis, P.N.; Tsakalof, A.; Karapanagiotis, I.; Zuburtikudis, I.; Panayiotou, C. Fabrication of super-hydrophobic surfaces for enhanced stone protection. Surf. Coat. Technol. 2009, 203, 1322-1328. [CrossRef]

53. Mosquera, M.J.; De Los Santos, D.M.; Rivas, T.; Sanmartín, P.; Silva, B. New nanomaterials for protecting and consolidating stone. J. Nano Res. 2009, 8, 1-12. [CrossRef]

54. Mosquera, M.J.; De Los Santos, D.M.; Rivas, T. Surfactant-synthesized ormosils with application to stone restoration. Langmuir 2010, 26, 6737-6745. [CrossRef] [PubMed]

55. Li, D.; Xu, F.; Liu, Z.; Zhu, J.; Zhang, Q.; Shao, L. The effect of adding PDMS-OH and silica nanoparticles on sol-gel properties and effectiveness in stone protection. Appl. Surf. Sci. 2013, 266, 368-374. [CrossRef]

56. Simionescu, B.; Olaru, M.; Aflori, M.; Cotofana, C. Silsesquioxane-based hybrid nanocomposite with self-assembling properties for porous limestones conservation. High Perform. Polym. 2010, 22, 42-55. [CrossRef]

57. Zornoza-Indart, A.; Lopez-Arce, P.; Leal, N.; Simão, J.; Zoghlami, K. Consolidation of a Tunisian bioclastic calcarenite: From conventional ethyl silicate products to nanostructured and nanoparticle based consolidants. Constr. Build. Mater. 2016, 116, 188-202. [CrossRef]

58. Bailly, M.; Kontopoulou, M.; El Mabrouk, K. Effect of polymer/filler interactions on the structure and rheological properties of ethylene-octene copolymer/nanosilica composites. Polymer 2010, 51, 5506-5515. [CrossRef] 
59. Hao, X.; Kaschta, J.; Pan, Y.; Liu, X.; Schubert, D.W. Intermolecular cooperativity and entanglement network in a miscible PLA/PMMA blend in the presence of nanosilica. Polymer 2016, 82, 57-65. [CrossRef]

60. Lepcio, P.; Ondreas, F.; Zarybnicka, K.; Zboncak, M.; Caha, O.; Jancar, J. Bulk polymer nanocomposites with preparation protocol governed nanostructure: The origin and properties of aggregates and polymer bound clusters. Soft Matter 2018, 14, 2094-2103. [CrossRef] [PubMed]

61. Esposito Corcione, C.; Striani, R.; Frigione, M. Hydrophobic photopolymerizable nanostructured hybrid materials: An effective solution for the protection of porous stones. Polym. Compos. 2015, 36, 1039-1047. [CrossRef]

62. Vecchiattini, R.; Fratini, F.; Rescic, S.; Riminesi, C.; Mauri, M.; Vicini, S. The marly limestone, a difficult material to restore: The case of the San Fruttuoso di Capodimonte Abbey (Genoa, Italy). J. Cult. Herit. 2018, in press. [CrossRef]

63. Facio, D.S.; Mosquera, M.J. Simple strategy for producing superhydrophobic nanocomposite coatings in situ on a building substrate. ACS Appl. Mater. Interfaces 2013, 5, 7517-7526. [CrossRef] [PubMed]

64. Corcione, C.E.; Striani, R.; Frigione, M. Novel hydrophobic free-solvent UV-cured hybrid organic-inorganic methacrylic-based coatings for porous stones. Prog. Org. Coat. 2014, 77, 803-812. [CrossRef]

65. Sow, C.; Riedl, B.; Blanchet, P. UV-waterborne polyurethane-acrylate nanocomposite coatings containing alumina and silica nanoparticles for wood: Mechanical, optical, and thermal properties assessment. J. Coat. Technol. Res. 2011, 8, 211-221. [CrossRef]

66. Nkeuwa, W.N.; Riedl, B.; Landry, V. Wood surfaces protected with transparent multilayer UV-cured coatings reinforced with nanosilica and nanoclay. Part I: Morphological study and effect of relative humidity on adhesion strength. J. Coat. Technol. Res. 2014, 11, 283-301. [CrossRef]

67. Nkeuwa, W.N.; Riedl, B.; Landry, V. Wood surfaces protected with transparent multilayer UV-cured coatings reinforced with nanosilica and nanoclay. Part II: Application of a standardized test method to study the effect of relative humidity on scratch resistance. J. Coat. Technol. Res. 2014, 11, 993-1011. [CrossRef]

68. Nikolic, M.; Lawther, J.M.; Sanadi, A.R. Use of nanofillers in wood coatings: A scientific review. J. Coat. Technol. Res. 2015, 12, 445-461. [CrossRef]

69. Kumar, A.; Petrič, M.; Kričej, B.; Žigon, J.; Tywoniak, J.; Hajek, P.; Škapin, A.S.; Pavlič, M. Liquefied-wood-based polyurethane-nanosilica hybrid coatings and hydrophobization by self-assembled monolayers of orthotrichlorosilane (OTS). ACS Sustain. Chem. Eng. 2015, 3, 2533-2541. [CrossRef]

70. Chu, Z.; Seeger, S. Robust superhydrophobic wood obtained by spraying silicone nanoparticles. RSC Adv. 2015, 5, 21999-22004. [CrossRef]

71. Munafò, P.; Goffredo, G.B.; Quagliarini, E. $\mathrm{TiO}_{2}$-based nanocoatings for preserving architectural stone surfaces: An overview. Constr. Build. Mater. 2015, 84, 201-218. [CrossRef]

72. Quagliarini, E.; Graziani, L.; Diso, D.; Licciulli, A.; D’Orazio, M. Is nano-TiO 2 alone an effective strategy for the maintenance of stones in Cultural Heritage? J. Cult. Herit. 2018, 30, 81-91. [CrossRef]

73. Gherardi, F.; Roveri, M.; Goidanich, S.; Toniolo, L. Photocatalytic nanocomposites for the protection of European architectural heritage. Materials 2018, 11, 65. [CrossRef] [PubMed]

74. Gherardi, F.; Goidanich, S.; Toniolo, L. Improvements in marble protection by means of innovative photocatalytic nanocomposites. Prog. Org. Coat. 2018, 121, 13-22. [CrossRef]

75. La Russa, M.F.; Rovella, N.; Alvarez de Buergo, M.; Belfiore, C.M.; Pezzino, A.; Crisci, G.M.; Ruffolo, S.A. Nano- $\mathrm{TiO}_{2}$ coatings for cultural heritage protection: The role of the binder on hydrophobic and self-cleaning efficacy. Prog. Org. Coat. 2016, 91, 1-8. [CrossRef]

76. La Russa, M.F.; Ruffolo, S.A.; Rovella, N.; Belfiore, C.M.; Palermo, A.M.; Guzzi, M.T.; Crisci, G.M. Multifunctional $\mathrm{TiO}_{2}$ coatings for cultural heritage. Prog. Org. Coat. 2012, 74, 186-191. [CrossRef]

77. Aflori, M.; Simionescu, B.; Bordianu, I.-E.; Sacarescu, L.; Varganici, C.-D.; Doroftei, F.; Nicolescu, A.; Olaru, M. Silsesquioxane-based hybrid nanocomposites with methacrylate units containing titania and/or silver nanoparticles as antibacterial/antifungal coatings for monumental stones. Mater. Sci. Eng. B 2013, 178, 1339-1346. [CrossRef]

78. Cappelletti, G.; Fermo, P.; Camiloni, M. Smart hybrid coatings for natural stones conservation. Prog. Org. Coat. 2015, 78, 511-516. [CrossRef]

79. Colangiuli, D.; Calia, A.; Bianco, N. Novel multifunctional coatings with photocatalytic and hydrophobic properties for the preservation of the stone building heritage. Constr. Build. Mater. 2015, 93, 189-196. [CrossRef] 
80. D'Orazio, L.; Grippo, A. A water dispersed Titanium dioxide/poly(carbonate urethane) nanocomposite for protecting cultural heritage: Preparation and properties. Prog. Org. Coat. 2015, 79, 1-7. [CrossRef]

81. Alfieri, I.; Lorenzi, A.; Ranzenigo, L.; Lazzarini, L.; Predieri, G.; Lottici, P.P. Synthesis and characterization of photocatalytic hydrophobic hybrid $\mathrm{TiO}_{2}-\mathrm{SiO}_{2}$ coatings for building applications. Build. Environ. 2017, 111, 72-79. [CrossRef]

82. Barberio, M.; Veltri, S.; Sokullu, E.; Xu, F.; Gauthier, M.A.; Antici, P. Preparation and characterization of nanostructured films: study of hydrophobicity and antibacterial properties for surface protection. In Advanced Processing and Manufacturing Technologies for Nanostructured and Multifunctional Materials II: A Collection of Papers Presented at the 39th International Conference on Advanced Ceramics and Composites; Ohji, T., Singh, M., Halbig, M., Eds.; Wiley Blackwell: Hoboken, NJ, USA, 2015; pp. 101-111.

83. Scalarone, D.; Lazzari, M.; Chiantore, O. Acrylic protective coatings modified with titanium dioxide nanoparticles: Comparative study of stability under irradiation. Polym. Degrad. Stab. 2012, 97, 2136-2142. [CrossRef]

84. Milanesi, F.; Cappelletti, G.; Annunziata, R.; Bianchi, C.L.; Meroni, D.; Ardizzone, S. Siloxane-TiO ${ }_{2}$ hybrid nanocomposites. The structure of the hydrophobic layer. J. Phys. Chem. C 2010, 114, 8287-8293. [CrossRef]

85. Petronella, F.; Pagliarulo, A.; Striccoli, M.; Calia, A.; Lettieri, M.; Colangiuli, D.; Curri, M.L.; Comparelli, R. Colloidal nanocrystalline semiconductor materials as photocatalysts for environmental protection of architectural stone. Crystals 2017, 7, 30. [CrossRef]

86. Kronlund, D.; Bergbreiter, A.; Meierjohann, A.; Kronberg, L.; Lindén, M.; Grosso, D.; Smått, J.-H. Hydrophobization of marble pore surfaces using a total immersion treatment method-Product selection and optimization of concentration and treatment time. Prog. Org. Coat. 2015, 85, 159-167. [CrossRef]

87. Luo, Y.; Xiao, L.; Zhang, X. Characterization of TEOS/PDMS/HA nanocomposites for application as consolidant/hydrophobic products on sandstones. J. Cult. Herit. 2015, 16, 470-478. [CrossRef]

88. Manoudis, P.N.; Karapanagiotis, I.; Tsakalof, A.; Zuburtikudis, I.; Kolinkeová, B.; Panayiotou, C. Superhydrophobic films for the protection of outdoor cultural heritage assets. Appl. Phys. A 2009, 97, 351-360. [CrossRef]

89. Forsthuber, B.; Müller, U.; Teischinger, A.; Grüll, G. Chemical and mechanical changes during photooxidation of an acrylic clear wood coat and its prevention using UV absorber and micronized $\mathrm{TiO}_{2}$. Polym. Degrad. Stab. 2013, 98, 1329-1338. [CrossRef]

90. Guo, H.; Klose, D.; Hou, Y.; Jeschke, G.; Burgert, I. Highly efficient UV protection of the biomaterial wood by a transparent $\mathrm{TiO}_{2} / \mathrm{Ce}$ xerogel. ACS Appl. Mater. Interfaces 2017, 9, 39040-39047. [CrossRef] [PubMed]

91. Moya, R.; Rodríguez-Zúñiga, A.; Vega-Baudrit, J.; Puente-Urbina, A. Effects of adding $\mathrm{TiO}_{2}$ nanoparticles to a water-based varnish for wood applied to nine tropical woods of Costa Rica exposed to natural and accelerated weathering. J. Coat. Technol. Res. 2017, 14, 141-152. [CrossRef]

92. Sun, Q.; Lu, Y.; Zhang, H.; Zhao, H.; Yu, H.; Xu, J.; Fu, Y.; Yang, D.; Liu, Y. Hydrothermal fabrication of rutile $\mathrm{TiO}_{2}$ submicrospheres on wood surface: An efficient method to prepare UV-protective wood. Mater. Chem. Phys. 2012, 133, 253-258. [CrossRef]

93. Rassam, G.; Abdi, Y.; Abdi, A. Deposition of $\mathrm{TiO}_{2}$ nano-particles on wood surfaces for UV and moisture protection. J. Exp. Nanosci. 2012, 7, 468-476. [CrossRef]

94. Pori, P.; Vilčnik, A.; Petrič, M.; Škapin, A.S.; Mihelčič, M.; Šurca Vuk, A.; Novak, U.; Orel, B. Structural studies of $\mathrm{TiO}_{2}$ / wood coatings prepared by hydrothermal deposition of rutile particles from $\mathrm{TiCl}_{4}$ aqueous solutions on spruce (Picea Abies) wood. Appl. Surf. Sci. 2016, 372, 125-138. [CrossRef]

95. Guo, H.; Bachtiar, E.V.; Ribera, J.; Heeb, M.; Schwarze, F.W.M.R.; Burgert, I. Non-biocidal preservation of wood against brown-rot fungi with a $\mathrm{TiO}_{2} / \mathrm{Ce}$ xerogel. Green Chem. 2018, 20, 1375-1382. [CrossRef]

96. Oliva, R.; Salvini, A.; Di Giulio, G.; Capozzoli, L.; Fioravanti, M.; Giordano, C.; Perito, B. $\mathrm{TiO}_{2}$-Oligoaldaramide nanocomposites as efficient core-shell systems for wood preservation. J. Appl. Polym. Sci. 2015, 132, 42047. [CrossRef]

97. Veronovski, N.; Verhovšek, D.; Godnjavec, J. The influence of surface-treated nano- $\mathrm{TiO}_{2}$ (rutile) incorporation in water-based acrylic coatings on wood protection. Wood Sci. Technol. 2013, 47, 317-328. [CrossRef]

98. Saha, S.; Kocaefe, D.; Sarkar, D.K.; Boluk, Y.; Pichette, A. Effect of $\mathrm{TiO}_{2}$-containing nano-coatings on the color protection of heat-treated jack pine. J. Coat. Technol. Res. 2011, 8, 183-190. [CrossRef]

99. Vlad Cristea, M.; Riedl, B.; Blanchet, P. Enhancing the performance of exterior waterborne coatings for wood by inorganic nanosized UV absorbers. Prog. Org. Coat. 2010, 69, 432-441. [CrossRef] 
100. Pinho, L.; Mosquera, M.J. Photocatalytic activity of $\mathrm{TiO}_{2}-\mathrm{SiO}_{2}$ nanocomposites applied to buildings: Influence of particle size and loading. Appl. Catal. B Environ. 2013, 134-135, 205-221. [CrossRef]

101. Crupi, V.; Fazio, B.; Gessini, A.; Kis, Z.; La Russa, M.F.; Majolino, D.; Masciovecchio, C.; Ricca, M.; Rossi, B.; Ruffolo, S.A.; et al. $\mathrm{TiO}_{2}-\mathrm{SiO}_{2}-\mathrm{PDMS}$ nanocomposite coating with self-cleaning effect for stone material: Finding the optimal amount of $\mathrm{TiO}_{2}$. Constr. Build. Mater. 2018, 166, 464-471. [CrossRef]

102. D'Amato, R.; Caneve, L.; Giancristofaro, C.; Persia, F.; Pilloni, L.; Rinaldi, A. Development of nanocomposites for conservation of artistic stones. Proc. Inst. Mech. Eng. Part N J. Nanoeng. Nanosyst. 2013, 228, $19-26$. [CrossRef]

103. Kapridaki, C.; Maravelaki-Kalaitzaki, P. $\mathrm{TiO}_{2}-\mathrm{SiO}_{2}-\mathrm{PDMS}$ nano-composite hydrophobic coating with self-cleaning properties for marble protection. Prog. Org. Coat. 2013, 76, 400-410. [CrossRef]

104. Kapridaki, C.; Pinho, L.; Mosquera, M.J.; Maravelaki-Kalaitzaki, P. Producing photoactive, transparent and hydrophobic $\mathrm{SiO}_{2}$-crystalline $\mathrm{TiO}_{2}$ nanocomposites at ambient conditions with application as self-cleaning coatings. Appl. Catal. B Environ. 2014, 156-157, 416-427. [CrossRef]

105. Pinho, L.; Mosquera, M.J. Titania-silica nanocomposite photocatalysts with application in stone self-cleaning. J. Phys. Chem. C 2011, 115, 22851-22862. [CrossRef]

106. Pinho, L.; Elhaddad, F.; Facio, D.S.; Mosquera, M.J. A novel $\mathrm{TiO}_{2}-\mathrm{SiO}_{2}$ nanocomposite converts a very friable stone into a self-cleaning building material. Appl. Surf. Sci. 2013, 275, 389-396. [CrossRef]

107. Ortelli, S.; Poland, C.A.; Baldi, G.; Costa, A.L. Silica matrix encapsulation as a strategy to control ROS production while preserving photoreactivity in nano-TiO $\mathrm{T}_{2}$. Environ. Sci. Nano 2016, 3, 602-610. [CrossRef]

108. Coltelli, M.-B.; Paolucci, D.; Castelvetro, V.; Bianchi, S.; Mascha, E.; Panariello, L.; Pesce, C.; Weber, J.; Lazzeri, A. Preparation of water suspensions of nanocalcite for Cultural Heritage applications. Nanomaterials 2018, 8, 254. [CrossRef] [PubMed]

109. Aldoasri, A.M.; Darwish, S.S.; Adam, A.M.; Elmarzugi, A.N.; Ahmed, M.S. Enhancing the durability of calcareous stone monuments of ancient Egypt using $\mathrm{CaCO}_{3}$ nanoparticles. Sustainability 2017, 9, 1392. [CrossRef]

110. Essa, A.M.M.; Khallaf, M.K. Biological nanosilver particles for the protection of archaeological stones against microbial colonization. Int. Biodeterior. Biodegrad. 2014, 94, 31-37. [CrossRef]

111. Essa, A.M.M.; Khallaf, M.K. Antimicrobial potential of consolidation polymers loaded with biological copper nanoparticles. BMC Microbiol. 2016, 16, 144. [CrossRef] [PubMed]

112. Verganelaki, A.; Kilikoglou, V.; Karatasios, I.; Maravelaki-Kalaitzaki, P. A biomimetic approach to strengthen and protect construction materials with a novel calcium-oxalate-silica nanocomposite. Constr. Build. Mater. 2014, 62, 8-17. [CrossRef]

113. Maravelaki, P.; Verganelaki, A. A hybrid consolidant of nano-hydroxyapatite and silica inspired from patinas for stone conservation. In Advanced Materials for the Conservation of Stone; Hosseini, M., Karapanagiotis, I., Eds.; Springer International Publishing: Cham, Switzerland, 2018; pp. 79-95. 